Article

\title{
Benchmarking of 316L Stainless Steel Manufactured by a Hybrid Additive/Subtractive Technology
}

\author{
Sheida Sarafan ${ }^{1} \oplus$, Priti Wanjara ${ }^{1, *} \mathbb{0}$, Javad Gholipour ${ }^{1}$, Fabrice Bernier ${ }^{1}$, Mahmoud Osman $^{1,2}$, Fatih Sikan ${ }^{1,2}$, \\ Josh Soost ${ }^{3}$, Robert Amos ${ }^{4}$, Prakash Patnaik ${ }^{1}$ and Mathieu Brochu ${ }^{2}$
}

1 National Research Council Canada, Transportation and Manufacturing Division, Montréal, QC H3T 1J4, Canada; sheida.sarafan@cnrc-nrc.gc.ca (S.S.); javad.gholipourbaradari@cnrc-nrc.gc.ca (J.G.); fabrice.bernier@cnrc-nrc.gc.ca (F.B.); mahmoud.osman@mail.mcgill.ca (M.O.); fatih.sikan@mail.mcgill.ca (F.S.); prakash.patnaik@nrc-cnrc.gc.ca (P.P.)

2 Department of Mining and Materials Engineering, McGill University, Montréal, QC H3A 0C5, Canada; mathieu.brochu@mcgill.ca

3 Matsuura Machinery USA Inc., St. Paul, MN 55102, USA; josh.soost@matsuurausa.com

4 Department of National Defence, Directorate of Technical Airworthiness and Engineering Support (DTAES), Ottawa, ON K1A 0K2, Canada; rob.amos2@forces.gc.ca

* Correspondence: priti.wanjara@cnrc-nrc.gc.ca

\section{check for}

Citation: Sarafan, S.; Wanjara, P.; Gholipour, J.; Bernier, F.; Osman, M.; Sikan, F.; Soost, J.; Amos, R.; Patnaik, P.; Brochu, M. Benchmarking of 316L Stainless Steel Manufactured by a Hybrid Additive/Subtractive Technology. J. Manuf. Mater. Process. 2022, 6, 30. https://doi.org/ $10.3390 /$ jmmp6020030

Academic Editors: Abhijit Chandra, Jonghyun Lee and Steven Y. Liang

Received: 25 January 2022

Accepted: 3 March 2022

Published: 5 March 2022

Publisher's Note: MDPI stays neutra with regard to jurisdictional claims in published maps and institutional affiliations.

Copyright: (C) 2022 by the National Research Council Canada. This article is an open access article distributed under the terms and conditions of the Creative Commons Attribution (CC BY) license (https:// creativecommons.org/licenses/by/ $4.0 /)$.

\begin{abstract}
This research study investigated the hybrid processing of 316L stainless steel using laser powder bed (LPB) processing with high-speed machining in the same build envelope. Benchmarking at four laser powers $(160 \mathrm{~W}, 240 \mathrm{~W}, 320 \mathrm{~W}$, and $380 \mathrm{~W})$ was undertaken by building additively with machining passes integrated sequentially after every ten deposited layers, followed by the final finishing of select surfaces. The final geometry was inspected against the computer-aided design (CAD) model and showed deviations smaller than $280 \mu \mathrm{m}$ for the as-built and machined surfaces, which demonstrate the good efficacy of hybrid processing for the net-shape manufacturing of stainless steel products. The arithmetic average roughness values for the printed surfaces, Ra (linear) and Sa (surface), were $11.4 \mathrm{um}$ and $14.9 \mathrm{um}$, respectively. On the other hand, the vertical and horizontal machined surfaces had considerably lower roughness, with Ra and Sa values ranging between $0.33 \mu \mathrm{m}$ and $0.70 \mu \mathrm{m}$. The $160 \mathrm{~W}$ coupon contained layered, interconnected lack of fusion defects which affected the density $\left(7.84 \mathrm{~g} \cdot \mathrm{cm}^{-3}\right)$, yield strength $(494 \mathrm{MPa})$, ultimate tensile strength $(604 \mathrm{MPa})$, Young's modulus (175 GPa), and elongation at break (17.3\%). By contrast, at higher laser powers, nearfull density was obtained for the $240 \mathrm{~W}\left(7.96 \mathrm{~g} \cdot \mathrm{cm}^{-3}\right), 320 \mathrm{~W}\left(7.94 \mathrm{~g} \cdot \mathrm{cm}^{-3}\right)$, and $380 \mathrm{~W}\left(7.92 \mathrm{~g} \cdot \mathrm{cm}^{-3}\right)$ conditions. This, combined with the isolated nature of the small pores, led to the tensile properties surpassing the requirements stipulated in ASTM F3184-16 for 316L stainless steel.
\end{abstract}

Keywords: hybrid manufacturing; laser powder bed fusion; 316L stainless steel; density; surface quality; X-ray micro-computed tomography; microstructure; hardness; tensile properties; fractography

\section{Introduction}

In the manufacturing sector, grade 316 L stainless steel (316LSS) is a ubiquitous alloy due to its durability, hygienic efficacy, and resistance to corrosion and high-temperature oxidation. These properties have allowed for the diverse applications of 316LSS, such as in marine engineering, aircraft and land vehicles within the defense sector, as well as in industries processing, medical devices, food, potable water, oil and gas, nuclear waste, chemicals, and petrochemicals, to name a few. The excellent combination of the physical, chemical, and mechanical properties of 316LSS is attributed to its chemistry, consisting of a high percentage of $\mathrm{Cr}(16-18.5 \%)$ and $\mathrm{Ni}(10-14 \%)$, as well as some Mo (2-3\%) added to this mix. Considering the recent listing of $\mathrm{Cr}$ as a critical raw material (CRM) [1], as well 
as the high cost of these alloying elements, the sustainable manufacturing of 316LSS has sparked high research interest in recent additive technologies [2-8]. Luckily, due to the low carbon content $(<0.03 \%$ maximum), 316LSS exhibits excellent weldability by fusion welding processes and is well-suited for the new paradigm of engineering with additive manufacturing (AM) strategies [9].

On the basis of available AM literature, Fayazfar et al. [10] reviewed powder-based additive technologies for the processing of steels and showed that the vast body of research has concentrated on the laser powder bed (LPB) processing of austenitic 316LSS [11-14]. The review by Baja et al. [11] on the microstructure and properties of steels processed by AM covered the research and challenges over the last decade to develop process windows for 316LSS using LPB technologies. More recently, Haghdadi et al. [15] reviewed the achievements and challenges for the AM of steels and indicated that more research is needed to address distortion (due to residual stresses), anisotropy, and pore formation in additively processed 316LSS. Of further concern for the AM of 316LSS is the low accuracy and high roughness of as-built surfaces that necessitate post-processing to attain high product performance [16] for certification in load-bearing, critical, or extreme environments. Unfortunately, owing to its low carbon and high alloy content, the inclination of this austenitic grade is to work harden at a very rapid rate, which poses considerable difficulties for the finish machining of additive parts to net-shape [17]. Undertaken separately and sequentially after AM, out-of-envelope machining poses additional challenges for aligning, workpiece-holding, and referencing, especially due to the lack of precise geometric datum in the as-built part [18].

Thus, in-envelope hybrid processing - which combines subtractive and additive technologies in a single machine-is an important research area for 316LSS. Hybrid additive/subtractive manufacturing (A/SM) using LPB technology, such as the Matsuura LUMEX Avance-25 system [19], can offer the additive building capability for complex structures in synergy with machined surfaces with high tolerance and low roughness to achieve the minimal waste of high-value alloys and/or CRMs, as well as conformance to high quality and tight geometric requirements. However, the A/SM of 316LSS brings new challenges, including the lack of know-how on the efficacy of dry micro-milling for the finish-machining of surfaces, the allowable engineering design properties, and the material-process-structure-property (MPSP) interrelationships. To date, Avegnon et al. [20] additively built 316LSS using a hybrid machine but undertook out-of-envelope milling to study the effectiveness of energy consumption as a process signature that could be correlated with the microhardness. Afazov et al. [21] used an A/SM machine for building 316LSS, but also investigated machining parameters out-of-envelope, using a stand-alone micro-milling center to assess the impacts on the material removal rates and the surface roughness. By contrast, Ahmad and Enemuoh [22] examined the influence of LPB and in-envelope micro-milling parameters on energy consumption during A/SM and developed an analytical model for the processing of 316LSS, but without considering the efficacy of the parametric set on the part quality and performance. Mutua [23] used an A/SM machine and applied only the LPB process to relate the build parameters to the surface quality, density, microstructure, and microhardness of 316LSS. Thus, a considerable gap exists in the understanding of the hybrid processing capability for 316LSS vis-à-vis surface quality after in-envelope machining, as well as the part quality and mechanical performance possible from the LPB process. The present study was therefore devised to explore hybrid manufacturing of 316LSS to identify a robust process window for A/SM through an evaluation of the powder characteristics, part distortion, surface finish, density, porosity features using X-ray micro-computed tomography $(\mu \mathrm{CT})$, macro/microstructure, bulk hardness, microhardness, and tensile properties. The mechanical properties and the MPSP interrelationships established in this research undoubtedly expand the current state-of-theart in hybrid manufacturing know-how on 316LSS, which is of importance for functional improvement of a broad range of products in various industries. In this study, the hybrid A/SM process was conducted on a Matsuura LUMEX Avance-25 system. 


\section{Experimental Procedure}

\subsection{Powder Characteristics}

The starting material used in this study was a commercial nitrogen gas-atomized SUS 316LSS powder (Matsuura stainless steel 316 L, St. Paul, MN, USA) with a nominal particle size of $-45 /+10 \mu \mathrm{m}$ and an elemental composition (in wt. $\%$ ) of $0.01 \% \mathrm{C}, 12.52 \% \mathrm{Ni}$, 0.70\% Mn, 17.18\% Cr, 2.04\% Mo, 0.93\% Si, 0.004\% S, 0.008\% P, 519 ppm N, 405 ppm $\mathrm{O}$, and balance Fe. Powder characterization was undertaken with a scanning electron microscope (SEM) (Hitachi SU3500, Fukuoka, Japan) to investigate the surface morphology. As revealed in Figure 1, the as-received powder showed a high volume of spherical, regularly-shaped particles, with a smooth surface and a few satellites. Moreover, a limited number of irregular and elongated particles was observed. The particle size distribution of the starting powder was assessed using a laser diffraction analyzer (Horiba LA-920, Kyoto, Japan); the three characteristic mean volume-weighted diameters of the fine $\left(\mathrm{D}_{10}\right)$, median $\left(D_{50}\right)$, and coarse $\left(D_{90}\right)$ particle fractions were determined to be $15 \mu \mathrm{m}, 22 \mu \mathrm{m}$, and $36 \mu \mathrm{m}$, respectively.

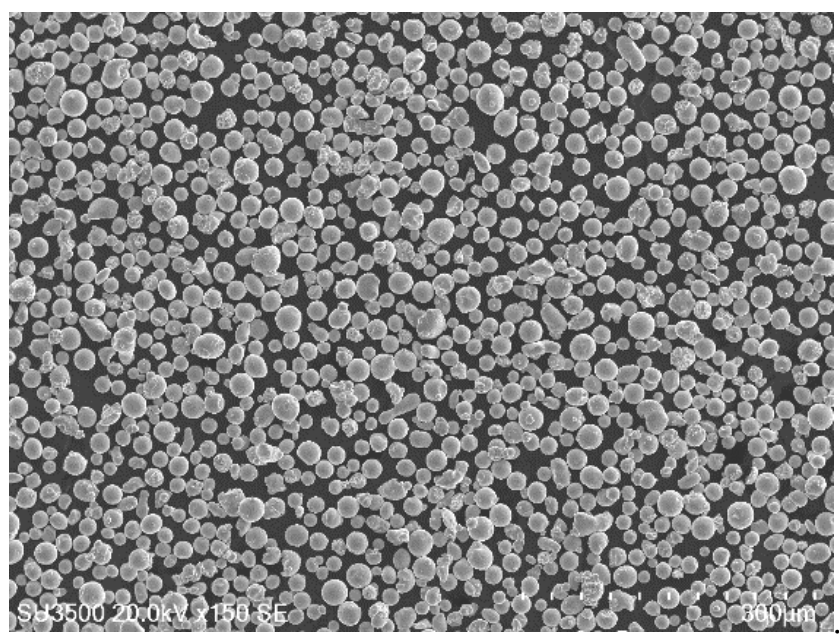

Figure 1. SEM micrograph of the 316LSS powder morphology.

The flowability of the 316LSS powder was assessed, respectively, with Hall and Carney funnels (Qualtech Products Industry-HFM1800 SS, Denver, CO, USA) by following the specifications in the ASTM B213 [24] and ASTM B964 standards [25]. The measured flow times through these funnels were $28.6 \mathrm{~s}$ (Hall) and $4.5 \mathrm{~s}$ (Carney) for $50 \mathrm{~g}$ of 316LSS powder. The apparent density of the powder was assessed to be $4.32 \mathrm{~g} \cdot \mathrm{cm}^{-3}$ (Hall) and $4.36 \mathrm{~g} \cdot \mathrm{cm}^{-3}$ (Carney) in accordance with ASTM standards [26,27]. Also, the static flow behavior of the powder was assessed from the conical heap of powders using image analysis. The static angle of repose for the 316LSS powder was comparable statistically to $34^{\circ}$ and sufficient to minimize defects during LPB AM by encouraging good powder spreading, according to Carr's classification of powder flowability [28].

A GranuDrum ${ }^{\circledR}$ rotating drum instrument was employed to quantify the cohesion occurring in the 316LSS powder during drum rotation by measuring the cohesive index of the particles from the fluctuations of the avalanche interface $[29,30]$. The analysis consisted of rotating a transparent drum filled with $50 \mathrm{~cm}^{3}$ of powder at angular velocities that ranged from 2 to 30 revolutions per minute (RPM) to induce powder flow. The measurements were obtained from backlighting the rotating drum and capturing images of the avalanche at different times using a CCD camera. In total, 40 images of the rotating drum were taken at an interval of 1 frame per second for each RPM. The built-in GranuDrum ${ }^{\circledR}$ software detected the air-powder interface location automatically and also computed the average interface position, as well as the fluctuations from this average position for each angular velocity. The fluctuations of the air-powder interface position were then directly related to the cohesion inside the drum and designated as the cohesion index. The evolution in 
the cohesive index for the 316LSS powder as a function of the rotating speed (Figure 2) indicated a relatively low cohesive index, which is inherently characteristic of good powder flowability, according to the findings [31] for powders with a cohesive index lower than 24 that exhibited free-flowing behavior and resulted in a homogenous and uniform layer during the spreading of the powder in the LPB process.

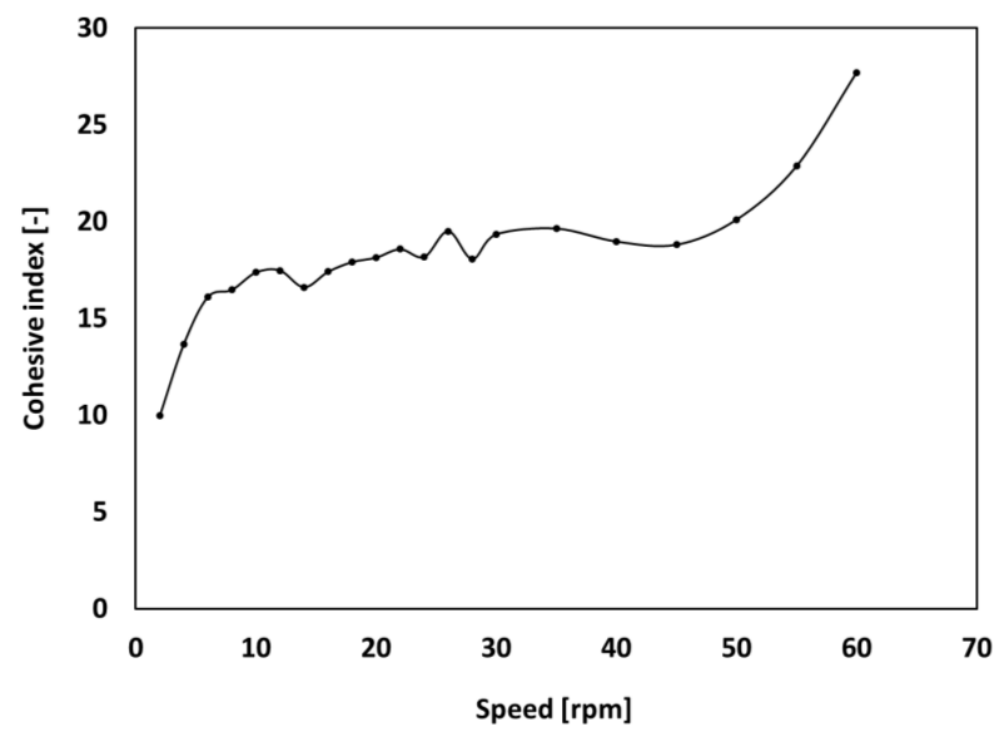

Figure 2. Cohesive index as a function of the rotation speed of the drum.

\subsection{Hybrid Additive/Subtractive Processing}

A/SM with the 316LSS powder was undertaken in a Matsuura LUMEX Avance-25 system that combines the LPB technology with high-speed milling. The powder bed platform or build plate was fabricated from 4140 wrought steel and had dimensions of $X=125 \mathrm{~mm}$, $\mathrm{Y}=175 \mathrm{~mm}$, and $\mathrm{Z}=30 \mathrm{~mm}$. This build plate was demagnetized to a magnetic field less than 0.2 Gauss using a surface demagnetizer (Electro-Matic model A13-1, R. B. Annis, Elmatco, Chicago, IL, USA) and then placed on the A/SM worktable. During the A/SM process, the temperature of the build platform was set to $50{ }^{\circ} \mathrm{C}$, and the build chamber was purged with nitrogen gas (of purity not lower than $97 \%$ ) to prevent the oxidization of the molten pool during laser melting. The deposition of layers on the build platform involved singledirection laser scanning with a $90^{\circ}$ rotation after every layer to build prismatic rectangular blocks (dimensions of $X=75 \mathrm{~mm} \times Y=25 \mathrm{~mm} \times Z=25 \mathrm{~mm}$ ) using different laser power (P) conditions-namely, $160 \mathrm{~W}, 240 \mathrm{~W}, 320 \mathrm{~W}$, and $380 \mathrm{~W}$-for both the rastering/infill and contouring passes (one of each per layer). The laser scan speed $(v)$ was $700 \mathrm{~mm} \cdot \mathrm{s}^{-1}$ and $1400 \mathrm{~mm} \cdot \mathrm{s}^{-1}$, respectively, for the infill and contour passes, while the values for the other parameters were fixed at a spot diameter $(\mathrm{d})$ of $200 \mu \mathrm{m}$, a layer height $\left(\mathrm{h}_{\mathrm{L}}\right)$ of $50 \mu \mathrm{m}$, and hatch spacing $\left(\mathrm{h}_{\mathrm{S}}\right)$ of $120 \mu \mathrm{m}$. Thus, with these fixed and varied parameters, for the laser powers selected in this study of $160 \mathrm{~W}, 240 \mathrm{~W}, 320 \mathrm{~W}$, and $380 \mathrm{~W}$, the corresponding infill energy density $\left(\mathrm{E}_{\text {density }}\right)$ values were $38.1 \mathrm{~J} \cdot \mathrm{mm}^{-3}, 57.1 \mathrm{~J} \cdot \mathrm{mm}^{-3}, 76.2 \mathrm{~J} \cdot \mathrm{mm}^{-3}$, and $90.5 \mathrm{~J} \cdot \mathrm{mm}^{-3}$, and the contour $E_{\text {density }}$ values were $19.0 \mathrm{~J} \cdot \mathrm{mm}^{-3}, 28.6 \mathrm{~J} \cdot \mathrm{mm}^{-3}, 38.1 \mathrm{~J} \cdot \mathrm{mm}^{-3}$, and $45.2 \mathrm{~J} \cdot \mathrm{mm}^{-3}$, respectively, using Equation (1):

$$
\mathrm{E}_{\text {density }}=\mathrm{P} /\left(\boldsymbol{v} \cdot \mathrm{h}_{\mathrm{L}} \cdot \mathrm{h}_{\mathrm{S}}\right)
$$

After depositing ten successive layers, remnant metal powder around the build was suctioned/removed and surface milling was then iterated [19]. A feed rate of $450 \mathrm{~mm} \cdot \mathrm{min}^{-1}$ with a $0.1 \mathrm{~mm}$ radial depth of cut for the vertical side-walls and $4 \mathrm{~mm}$ for the horizontal top surface, based on the manufacturer's recommended settings, was applied. The four prismatic blocks produced by A/SM consisted of two as-built (B) faces and three built-andmachined (B\&M) faces, as displayed in Figure 3. 


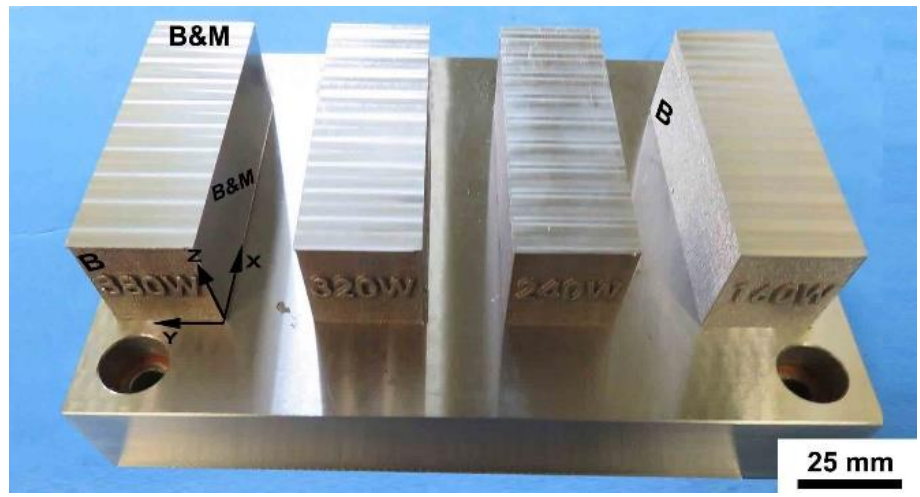

Figure 3. Prismatic blocks produced by A/SM, showing the as-built (B) and built-and-machined (B\&M) faces.

\subsection{Sample Preparation and Qualification Testing}

An optical three-dimensional (3D) scanning system (ATOS Core, GOM, Germany) was used to inspect the geometrical dimensions of the four prismatic rectangular blocks (still attached to the build platform) after A/SM to assess the conformity/accuracy against the 3D CAD model. Then, the blocks were separated from the build platform using electro-discharge machining (EDM) (FANUC Robocut C400iB, Oshino-mura, Yamanashi, Japan) with a brass wire of $0.2 \mathrm{~mm}$ in diameter. A portable Surftest SJ-210 (4 mN type profilometer, Mitutoyo Aurora, IL, USA) with a tip radius of $2 \mu \mathrm{m}$ was utilized to assess the surface quality of the blocks on both the as-built, as well as the built-and-machined faces by measuring the primary profile to calculate the roughness parameters, which included the arithmetic mean height $(\mathrm{Ra})$, root mean square height $(\mathrm{Rq})$, and maximum height (Rz). It is noteworthy that the total measured length of the primary profile was $4 \mathrm{~mm}$ and the roughness profile was derived from the primary profile by suppressing the long wave component using the high-pass filter with a cut-off of $\lambda_{c}=0.8 \mathrm{~mm}$. Moreover, a 3D laser scanning confocal microscope (Keyence VK-X250, Osaka, Japan) was used to measure the equivalent areal roughness parameters-namely $\mathrm{Sa}, \mathrm{Sq}$, and $\mathrm{Sz}$ - on the different surfaces in accordance with ISO 25178-2 [32].

Each block was then divided into two sections (S1 and S2) alongside the XZ plane, as illustrated in Figure 4a. Samples were extracted from section S1 to evaluate the relative density, porosity by X-ray $\mu \mathrm{CT}$, and tensile properties, while section $\mathrm{S} 2$ was utilized to extract samples for metallography and hardness testing. The subsequent EDM of section S1 was used to extract three samples through the thickness (in the BD) of each block $(160 \mathrm{~W}, 240 \mathrm{~W}, 320 \mathrm{~W}$, and $380 \mathrm{~W})$, as illustrated in Figure 4a. These were then machined to dog-bone-shaped tensile samples with a $25 \mathrm{~mm}$ gage length (Figure $4 \mathrm{~b}$ ), according to the guidelines for a standard sub-size geometry in ASTM E8M-21 [33]. Prior to static tensile testing, these samples were inspected non-destructively for porosity and density using three methods: Archimedes [34], helium gas pycnometry [35], and X-ray $\mu \mathrm{CT}$. Density measurements, using the Archimedes and He gas pycnometry methods, were undertaken with an AND BM-500 density measurement kit and an Anton Paar Ultrapyc 5000 system, respectively. For the calculation of relative density, a theoretical value of $8.0 \mathrm{~g} / \mathrm{cm}^{3}$ was used for 316LSS [36]. The pore size and porosity distribution were evaluated on the gage length of the tensile samples using an HMXST 225 X-ray $\mu \mathrm{CT}$ system (Nikon Metrology Inc., USA) equipped with a Perkin-Elmer 1621AN CsI $(2000 \times 2000$ pixels, $40 \mathrm{~cm} \times 40 \mathrm{~cm}$, $200 \mu \mathrm{m} /$ pixel) detector panel. The X-ray source was operated with a voltage of $120 \mathrm{kV}$, a current of $58 \mu \mathrm{A}$, and an exposure time of $1000 \mathrm{~ms}$ with a $0.25 \mathrm{~mm} \mathrm{Ag}$ filter. The scans were undertaken at two magnification levels: (1) a low magnification level of 10.9X to permit the visualization of the full gage length, which gave a voxel size of $18.4 \mu \mathrm{m}$; and (2) a higher magnification scan at 46X, which gave a voxel size of $4.4 \mu \mathrm{m}$. For image analysis, 
Dragonfly software was utilized for 3D reconstruction to analyze the volume and size distribution of the pores using manual segmentation.

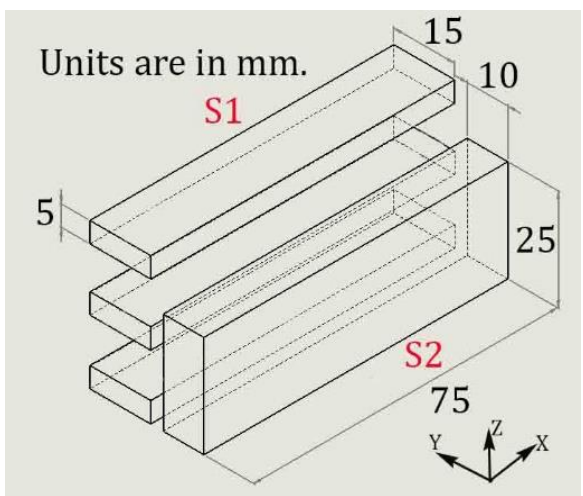

(a)

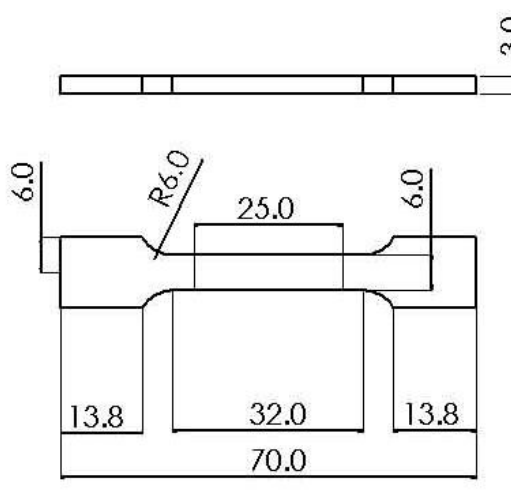

(b)

Figure 4. Schematic diagrams showing (a) extraction methodology, and (b) the geometry of the tensile samples.

The twelve tensile samples — three for each laser power $(160 \mathrm{~W}, 240 \mathrm{~W}, 320 \mathrm{~W}$, and $380 \mathrm{~W})$ that were extracted from the top, middle, and bottom of section S1 in the four as-built blocks-were then tested using a $250 \mathrm{kN}$ testing frame integrated with a laser extensometer (MTS Systems Corporation, Eden Prairie, MN, USA). Tensile testing was performed at room temperature using displacement control at a rate of $0.4 \mathrm{~mm} \cdot \mathrm{min}^{-1}$ until rupture. The tensile properties of 316LSS that were evaluated from the engineering stress-strain curves included the yield strength or $0.2 \%$ proof stress (YS), ultimate tensile strength (UTS), percent elongation (EL), and Young's modulus (YM). The fractured surfaces of the tensile samples were examined after testing using an SEM at $15 \mathrm{keV}$ to understand the role of the different pore structures (isolated, interconnected).

By contrast, samples for metallography and hardness testing (Figure 4a) were extracted from the S2 sections of the four blocks produced at the different laser powers. For conceptualizing the 3D macro/microstructures of the 316LSS, metallographic samples from the three orthogonal planes $(X-Y, X-Z, Y-Z)$ were extracted for each laser power $(160 \mathrm{~W}, 240 \mathrm{~W}$, $320 \mathrm{~W}$, and $380 \mathrm{~W}$ ) using a precision low-speed diamond cut-off saw. The metallographic preparation of the samples involved mounting in cold resin, followed by grinding and polishing automatically to a finish of $0.04 \mu \mathrm{m}$, as detailed in [37]. While the characteristics of the pores were examined on polished surfaces, the general microstructure was revealed by immersing the samples in an electrolytic etch at room temperature for $30 \mathrm{~s}$ in a solution of $10 \%$ oxalic acid with a voltage of $15 \mathrm{~V}$ at a current of $1.6 \mathrm{~A}$ using an austenitic stainless steel cathode.

The phase analysis of the as-built 316LSS samples was investigated by X-ray diffraction (XRD) and magnetic induction methods. A Bruker D8 Discover diffractometer (Karlsruhe, Germany) with Co-K $\alpha$ radiation (wavelength of $0.178897 \mathrm{~nm}$ ) at a voltage of $35 \mathrm{kV}$ and $45 \mathrm{~mA}$ was used to obtain XRD patterns of the as-built 316LSS samples at room temperature.

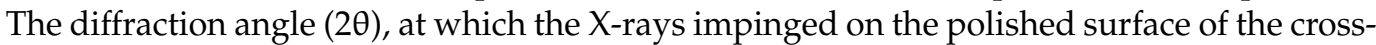
sections prepared for metallography, was varied from $20^{\circ}$ to $110^{\circ}$ at a scan step of $0.005 \mathrm{~s}$. The DiffracPlus software of the diffractometer allowed the initial processing of the diffraction pattern to differentiate the peaks corresponding to the austenite $(\gamma)$, delta $(\delta)$-ferrite, and martensite $\left(\alpha^{\prime}\right)$ phases. Moreover, the $\delta$-ferrite content in the samples was examined using a Feritscope ${ }^{\circledR}$ (Model MP3C, Helmut Fisher $\left.\mathrm{GmbH}\right)$. This non-destructive inspection device is based on a magnetic induction method that was originally designed to measure the $\delta$-ferrite content in austenitic stainless steel welds. In this magneto-inductive test method, an electromagnetic field generated by a coil interacts with the magnetic constituents in the sample, including $\delta$-ferrite and/or any retained/strain-induced $\alpha^{\prime}$-martensite in 316LSS. The magnetization of these phases induces an electrical potential difference in a second 
coil and this output voltage is linearly related to the magnetic permeability of the sample. It has been reported that this method is a direct and reliable way to quantify low amounts (roughly $0.1 \%$ ) of $\delta$-ferrite [38]. To obtain a reliable quantitative measurement, a calibration was performed using certified standard sets (Helmut Fischer) with traceability to The Welding Institute (TWI, UK) secondary standards, according to the method described in DIN EN ISO 8249 [39] and ANSI/AWS A4.2 [40]. The Feritscope measurements were performed on the as-built and/or machined surfaces. Roughly ten different points were measured for each laser power and reported as the percentage of ferrite.

The hardness of the 316LSS samples produced using different laser powers was assessed using Rockwell and Vickers testing according to specifications given respectively in ASTM standards E18-20 [41] and E384-17 [42]. The bulk hardness of the samples was evaluated by Rockwell testing on the C-scale, which is typically used for steels. For each laser power $(160 \mathrm{~W}, 240 \mathrm{~W}, 320 \mathrm{~W}$, and $380 \mathrm{~W})$, at least 5 measurements were performed-using a diamond rounded-tip cone indenter (ground at $120^{\circ}$ ) with a diameter of $0.2 \mathrm{~mm}$ and a minor load of $10 \mathrm{~kg}$, followed by a major load of $150 \mathrm{~kg}$ - to calculate the average Rockwell $\mathrm{C}$ hardness (HRC). Vickers microhardness testing was carried out on polished (mirrorfinished) metallographic samples using an automated hardness tester (Struers DuraScan 80, Ballerup, Denmark) [43] with a load of $500 \mathrm{~g}$, an indent spacing of $0.8 \mathrm{~mm}$, and a dwell period of $15 \mathrm{~s}$. For each sample condition, the reported Vickers hardness profile across the cross-sections was averaged from three measurements for each data point.

\section{Results and Data Analysis}

\subsection{Printed Geometry Versus CAD Model Qualification}

During LPB processing, the repetitive cycles of rapid, layer-wise heating and cooling induce large temperature gradients and thermal stresses that can distort the as-built geometry relative to the CAD model. To evaluate the geometric stability and accuracy of the four blocks built by A/SM, inspection with an optical 3D scanner (ATOS Core) was undertaken (before EDM from the build platform), so as to obtain 3D coordinate measurement data of the build in the form of a 3D mesh for analysis and comparison with the reference CAD data using a best-fit algorithm. Figure 5 describes the inspection results for the geometry of the four 316LSS blocks, charted via a contour map with color levels representing deviations ranging from $0.3 \mathrm{~mm}$ to $-0.3 \mathrm{~mm}$. The as-built surfaces (i.e., B faces labeled with deviation values in Figure 5a) exhibited geometric deviations ranging from $80 \mu \mathrm{m}$ to $280 \mu \mathrm{m}$, which could be significantly decreased after machining (i.e., B\&M faces labeled with deviation values in Figure $5 \mathrm{~b}$ ) to values under $10 \mu \mathrm{m}$. This demonstrates the high efficacy of the in-envelope milling process for dimensional and shape accuracy. The lower accuracy of the as-built surfaces concurs with findings from thermal simulations that have pointed to the key LPB process parameters $\left(\mathrm{P}, \mathrm{v}, \mathrm{h}_{\mathrm{L}}, \mathrm{h}_{\mathrm{S}}\right)$ affecting the part geometry [44].

To inspect the quality of the surface finish on the four 316LSS blocks produced by $\mathrm{A} / \mathrm{SM}$, the average values of the different linear profile and areal roughness parameters were evaluated on the as-built and machined surfaces, as tabulated in Table 1. In this study, both areal and profile parameters were measured. The former has the competitive advantage of extending the evaluated dataset laterally over a surface area. However, the latter method directly traces the surface with a mechanical probe and provides comparable data to the longstanding norms / practice used in manufacturing industries for specifying surface quality required for geometric dimensioning and tolerancing (GD\&T) [45,46]. 
a

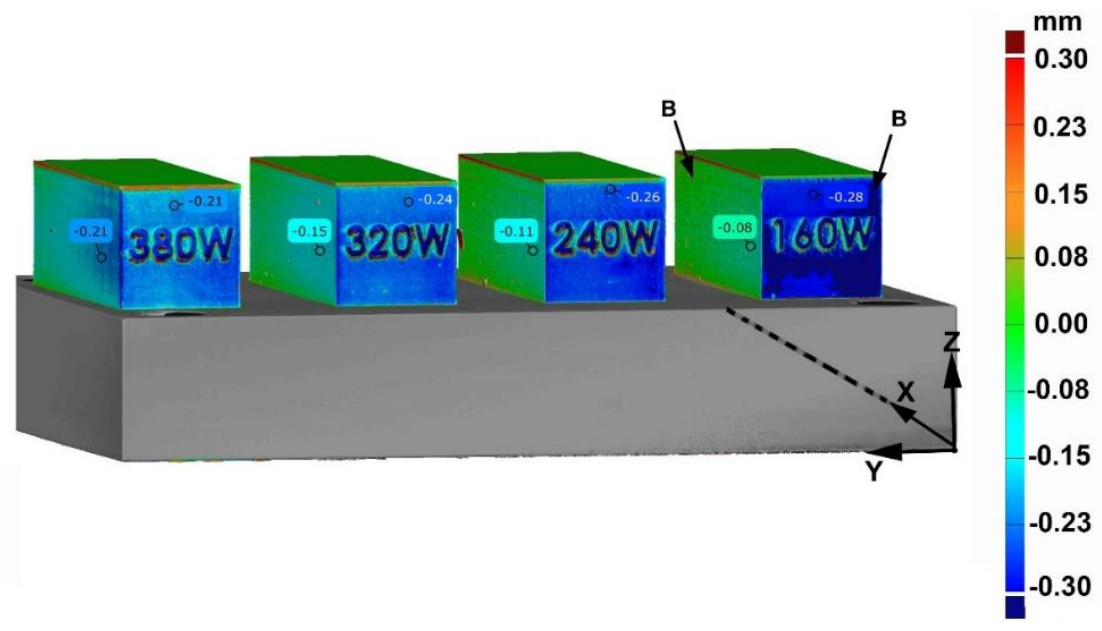

b

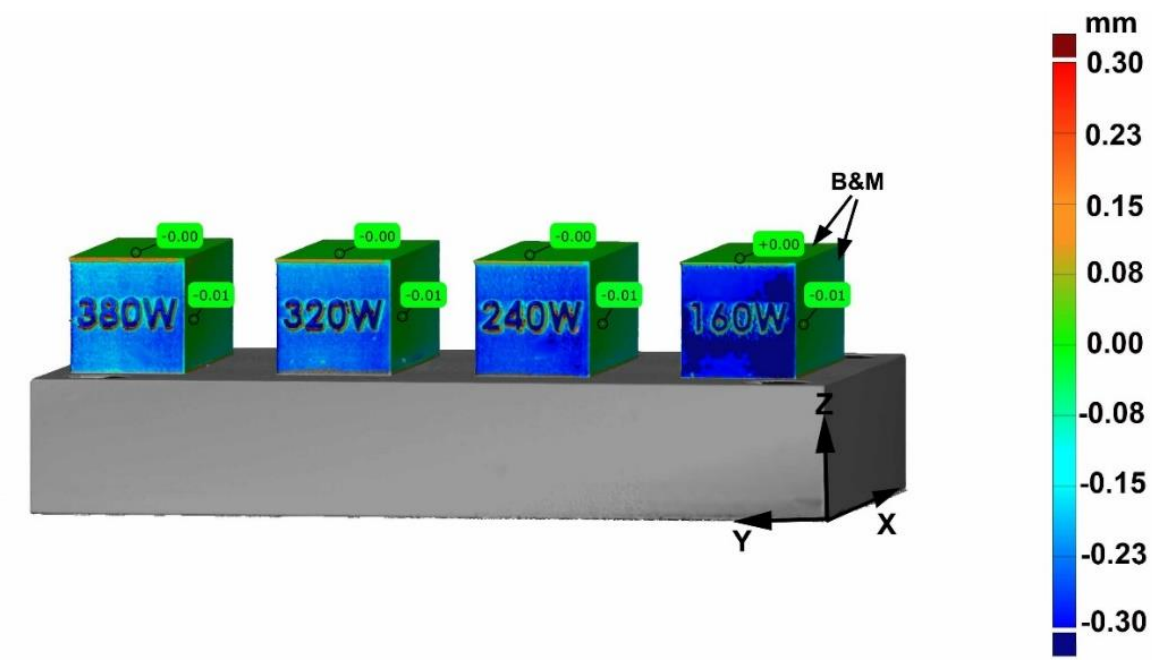

Figure 5. Contour plots of the geometric deviations on the (a) as-built (B) and (b) built-and-machined (B\&M) surfaces of the four blocks fabricated at the different laser powers.

Table 1. Profile and areal roughness parameters measured on the different vertical side-walls and horizontal top-faces of the four blocks.

\begin{tabular}{|c|c|c|c|c|c|c|c|c|c|}
\hline \multirow{2}{*}{$\begin{array}{l}\text { Condition/ } \\
\text { Face }\end{array}$} & \multirow{2}{*}{$\begin{array}{l}\text { Power } \\
\text { (W) }\end{array}$} & \multicolumn{2}{|c|}{$\mathrm{E}_{\text {density }}\left(\mathrm{J} \cdot \mathrm{mm}^{-3}\right)$} & \multicolumn{3}{|c|}{ Profile $(\mu \mathrm{m})$} & \multicolumn{3}{|c|}{ Areal $(\mu \mathrm{m})$} \\
\hline & & Infill & Contour & $\mathbf{R a}$ & $\mathrm{Rq}$ & $\mathrm{Rz}$ & Sa & $\mathrm{Sq}$ & $\mathrm{Sz}$ \\
\hline \multirow{4}{*}{$\begin{array}{l}\text { As-built vertical } \\
\text { side-walls }\end{array}$} & 160 & 38.1 & 19.0 & 11.67 & 14.34 & 62.07 & 16.88 & 21.75 & 144.77 \\
\hline & 240 & 57.1 & 28.6 & 11.22 & 13.59 & 57.52 & 13.23 & 16.63 & 84.94 \\
\hline & 320 & 76.2 & 38.1 & 11.12 & 13.14 & 56.38 & 13.38 & 16.15 & 89.80 \\
\hline & 380 & 90.5 & 45.2 & 11.73 & 14.39 & 62.45 & 16.15 & 19.45 & 106.40 \\
\hline \multirow{4}{*}{$\begin{array}{c}\text { Machined } \\
\text { vertical side-walls }\end{array}$} & 160 & 38.1 & 19.0 & 0.33 & 0.43 & 2.32 & 0.42 & 0.54 & 5.04 \\
\hline & 240 & 57.1 & 28.6 & 0.38 & 0.48 & 2.37 & 0.38 & 0.48 & 6.09 \\
\hline & 320 & 76.2 & 38.1 & 0.62 & 0.78 & 3.98 & 0.38 & 0.50 & 5.50 \\
\hline & 380 & 90.5 & 45.2 & 0.65 & 0.81 & 3.88 & 0.70 & 0.87 & 6.86 \\
\hline \multirow{4}{*}{$\begin{array}{l}\text { Machined horizontal } \\
\text { top-face }\end{array}$} & 160 & 38.1 & 19.0 & 0.36 & 0.48 & 2.64 & 0.35 & 0.45 & 5.35 \\
\hline & 240 & 57.1 & 28.6 & 0.47 & 0.55 & 2.57 & 0.36 & 0.47 & 5.02 \\
\hline & 320 & 76.2 & 38.1 & 0.59 & 0.76 & 4.00 & 0.36 & 0.46 & 4.11 \\
\hline & 380 & 90.5 & 45.2 & 0.55 & 0.72 & 3.58 & 0.45 & 0.54 & 4.45 \\
\hline
\end{tabular}


For the as-built vertical side-wall surfaces, the roughness parameters (Table 1) showed a minor dependence on the laser power over the process window studied in this work, namely with the contour $E_{\text {density }}$ ranging from $19.0 \mathrm{~J} \cdot \mathrm{mm}^{-3}$ to $45 \mathrm{~J} \cdot \mathrm{mm}^{-3}$. The surface roughness on the as-printed vertical side-walls exhibited $\mathrm{Sz}$ values of $144.77 \mu \mathrm{m}$ and $106.4 \mu \mathrm{m}$, respectively, at the lowest and highest conditions of $160 \mathrm{~W}\left(19.0 \mathrm{~J} \cdot \mathrm{mm}^{-3}\right)$ and $380 \mathrm{~W}\left(45 \mathrm{~J} \cdot \mathrm{mm}^{-3}\right)$. By contrast, intermediary conditions at laser powers of $240 \mathrm{~W}$ $\left(57.1 \mathrm{~J} \cdot \mathrm{mm}^{-3}\right)$ and $320 \mathrm{~W}\left(76.2 \mathrm{~J} \cdot \mathrm{mm}^{-3}\right)$ resulted in more even surfaces with $\mathrm{Sz}$ values of 85-90 $\mu \mathrm{m}$. The typical Ra $(11.12 \mu \mathrm{m}$ to $11.73 \mu \mathrm{m})$ and Sa $(13.23 \mu \mathrm{m}$ to $16.88 \mu \mathrm{m})$ values measured in the present study for the as-built surfaces of 316LSS corroborated well with the reported Ra of $9.95 \mu \mathrm{m}$ by Mutua [23] and $14.05 \mu \mathrm{m}$ by Avegnon et al. [20] for samples built using the Matsuura LUMEX Avance-25 system.

After in-envelope micro-milling of the four blocks, the roughness (Table 1) on the vertical side-walls had $\mathrm{Ra}$ and Sa values that ranged from $0.33 \mu \mathrm{m}$ to $0.65 \mu \mathrm{m}$ and $0.35 \mu \mathrm{m}$ to $0.7 \mu \mathrm{m}$, respectively. The in-envelope machined horizontal top-faces were comparable with $\mathrm{Ra}$ and Sa values ranging from $0.36 \mu \mathrm{m}$ to $0.59 \mu \mathrm{m}$ and $0.35 \mu \mathrm{m}$ to $0.45 \mu \mathrm{m}$, respectively. Relative to the as-built surfaces (having average values for Ra and Sa of $11.4 \mu \mathrm{m}$ and $14.9 \mu \mathrm{m}$, respectively), these $\mathrm{Ra}$ and Sa values after the in-envelope micro-milling of the 316LSS surfaces were more than an order of magnitude lower and similar to finish qualities achievable on polished surfaces [47,48]. It is noteworthy that Afazov et al. [21] reported minimized $\mathrm{Ra}$ values between $0.55 \mu \mathrm{m}$ and $0.65 \mu \mathrm{m}$ when using optimized milling parameters on an out-of-envelope system (i.e., Kern Evo Ultra-Precision CNC Machine) to machine 316LSS samples as-built using a Matsuura LUMEX Avance-25 system. The comparable roughness attained in the present study demonstrates the good capability, processing flexibility, and high efficacy possible with in-envelope hybrid processing.

\subsection{Density Characteristics}

The density of the as-built 316LSS was measured by the Archimedes and helium gas pycnometry methods, and the data are tabulated in Table 2 for the laser powers used in this study. The lowest densities of $7.84 \mathrm{~g} \cdot \mathrm{cm}^{3}$ (Archimedes) and $7.97 \mathrm{~g} \cdot \mathrm{cm}^{3}$ (gas pycnometry) were measured for the lowest laser power of $160 \mathrm{~W}\left(38.1 \mathrm{~J} \cdot \mathrm{mm}^{-3}\right)$. On the basis of these density measurements, the relative density ranged between $98.0 \%$ and $99.6 \%$, indicating a porosity percentage of $0.4 \%-2 \%$. An examination of the X-ray $\mu \mathrm{CT}$ scans of the $160 \mathrm{~W}$ sample (Figure 6a) revealed that this porosity was related to balling and/or lack of fusion defects (i.e., black regions in images) that were large, irregular, and interconnected. It is worth mentioning that the relative density of $98 \%$, measured for the $160 \mathrm{~W}$ condition on the basis of the average Archimedes density, resembles more closely the porosity level in the $\mu \mathrm{CT}$ scans. This points to an overestimation of the density values by the helium gas pycnometry method, which may be attributed to the substantially lower dynamic viscosity of helium (by 40 times) relative to water, which leads to a higher penetration of the open porosity, as explained in [49].

Table 2. Density of 316LSS produced by A/SM.

\begin{tabular}{|c|c|c|c|c|c|}
\hline $\begin{array}{c}\text { Laser Power } \\
\text { (W) }\end{array}$ & $\begin{array}{c}\text { Infill } \mathrm{E}_{\text {density }} \\
\left(\mathrm{J} \cdot \mathrm{mm}^{-3}\right)\end{array}$ & $\begin{array}{c}\text { Archimedes } \\
\text { Density }\left(\mathrm{g} \cdot \mathrm{cm}^{-3}\right)\end{array}$ & STD & $\begin{array}{c}\text { Pycnometer } \\
\text { Density }\left(\mathrm{g} \cdot \mathrm{cm}^{-3}\right)\end{array}$ & STD \\
\hline 160 & 38.1 & 7.84 & 0.01 & 7.97 & 0.05 \\
\hline 240 & 57.1 & 7.96 & 0.03 & 8.02 & 0.04 \\
\hline 320 & 76.2 & 7.94 & 0.01 & 8.02 & 0.05 \\
\hline 380 & 90.5 & 7.92 & 0.02 & 8.04 & 0.04 \\
\hline
\end{tabular}



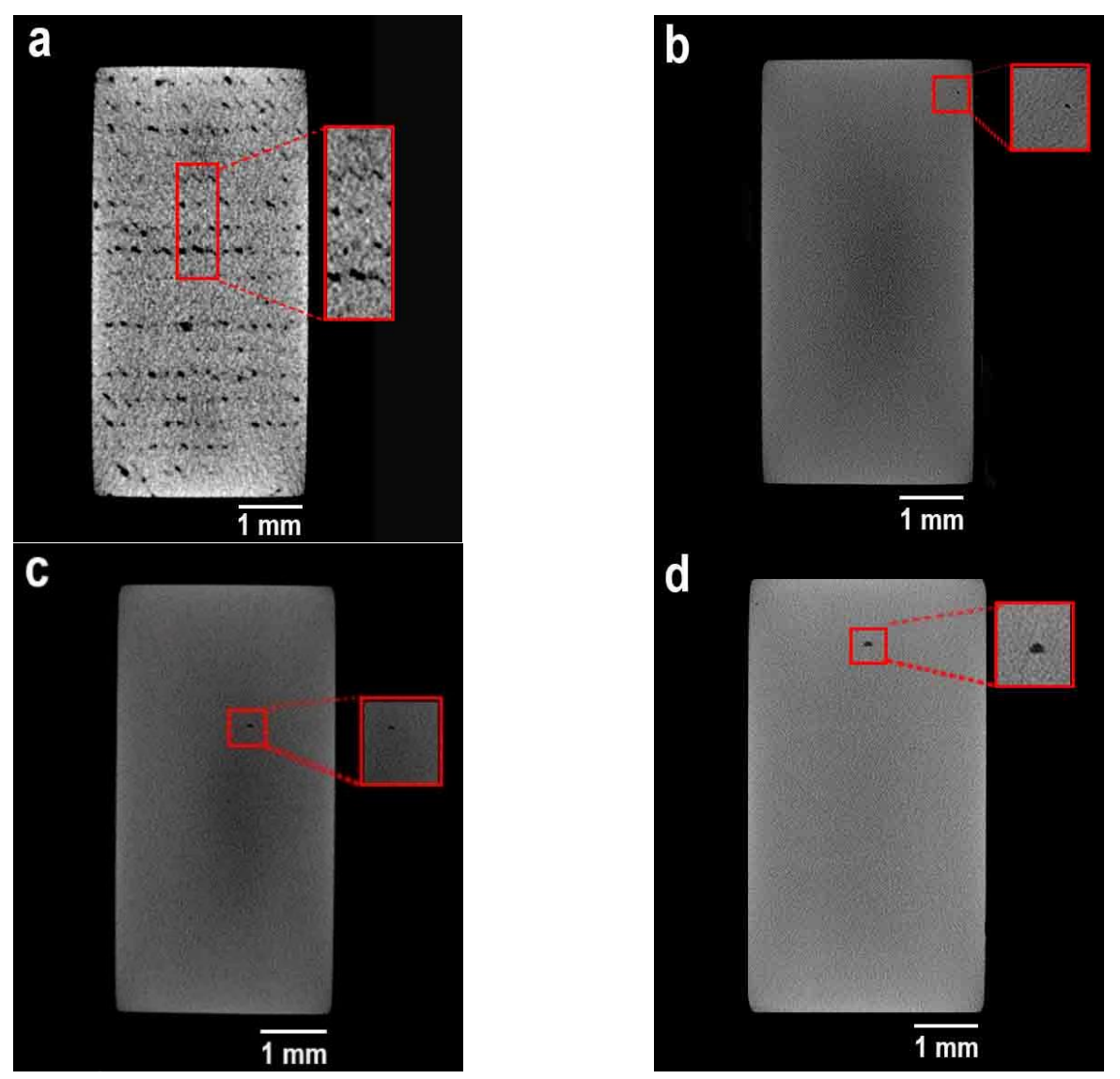

Figure 6. Representative TD images from X-ray $\mu \mathrm{CT}$ scanning of the gage length in the tensile samples for laser powers of (a) $160 \mathrm{~W}$, (b) $240 \mathrm{~W}$, (c) $320 \mathrm{~W}$, and (d) $380 \mathrm{~W}$. The resolution is $18.4 \mu \mathrm{m}$ voxel size for (a) and $4.4 \mu \mathrm{m}$ voxel size for $(\mathbf{b}-\mathbf{d})$.

By contrast, for the $240 \mathrm{~W}\left(57.1 \mathrm{~J} \cdot \mathrm{mm}^{-3}\right), 320 \mathrm{~W}\left(76.2 \mathrm{~J} \cdot \mathrm{mm}^{-3}\right)$, and $380 \mathrm{~W}\left(90.5 \mathrm{~J} \cdot \mathrm{mm}^{-3}\right)$ conditions, the presence of small spherical and isolated pores were observed in the $\mu \mathrm{CT}$ scans (Figure $6 \mathrm{~b}-\mathrm{d}$ ). On the basis of the Archimedes density values, the relative densities for the $240 \mathrm{~W}(99.5 \%), 320 \mathrm{~W}(99.3 \%)$, and $380 \mathrm{~W}(99.0 \%)$ conditions were higher than the $160 \mathrm{~W}$ condition (98.0\%). Moreover, the pores were observed to be finest for the $240 \mathrm{~W}$ condition, as shown in Figure 7, and some minor coarsening was apparent with increasing laser power (Figures 6b-d and 7). Specifically, increasing the laser power from $160 \mathrm{~W}$ to $240 \mathrm{~W}$ led to a higher infill $E_{\text {density }}$ that improved the densification of the powder during LPB processing, as revealed in Figure 6 by the absence of the lack of fusion pores and in Figure 7 by the small size of the pores, i.e., less than $30 \mu \mathrm{m}$. Further increases in the laser power to $320 \mathrm{~W}$ resulted in relatively similar porosity characteristics, as those observed for the $240 \mathrm{~W}$ condition, but the size of the pores was larger, ranging up to $60 \mu \mathrm{m}$. At the maximum power of $380 \mathrm{~W}$ (and infill $\mathrm{E}_{\text {density }}$ of $90.5 \mathrm{~J} \cdot \mathrm{mm}^{-3}$ ) used in this study, the coarsening of the pores was obvious, with typical sizes of up to $100 \mu \mathrm{m}$. Nonetheless, on the basis of the $\mu \mathrm{CT}$ scans (Figure 6) and the standard deviations measured on the density datasets (Archimedes and gas pycnometry in Table 2), the relative density and porosity percentage can be considered statistically comparable (from a t-test with an alpha level of 0.05 ) for the $240 \mathrm{~W}, 320 \mathrm{~W}$, and $380 \mathrm{~W}$ laser powers when factoring in the error margins of the test methods. This process window to achieve near-full density in 316LSS by A/SM concurs reasonably well with the highest relative density of $99.2 \%$ reported by Mutua [23] at $320 \mathrm{~W}$ and $77.92 \mathrm{~J} \cdot \mathrm{mm}^{-3}$. 


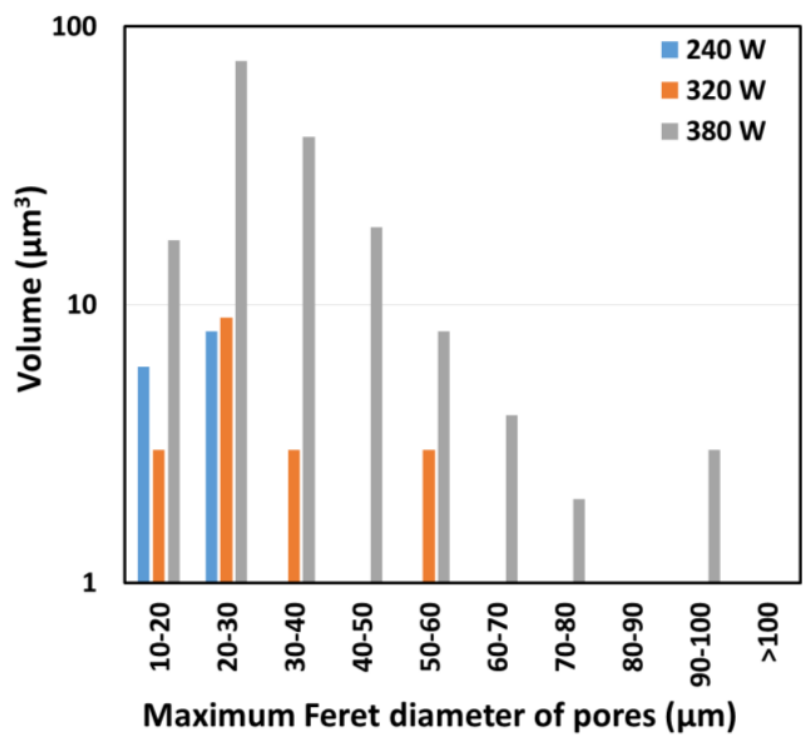

Figure 7. Plot of the pore volume versus their maximum Feret diameter determined from $\mu \mathrm{CT}$ analyzes of the samples produced at $240 \mathrm{~W}, 320 \mathrm{~W}$, and $380 \mathrm{~W}$.

\subsection{Macro/Microstructures}

Figure 8 illustrates the results of reconstructing representative 3D macrostructures from two-dimensional (2D) optical images of the etched metallographic cross-sections in the three orthogonal planes- the $X-Y$ plane in the transverse direction (TD) which is normal to $\mathrm{X}-\mathrm{Z}$ and $\mathrm{Y}-\mathrm{Z}$ planes in the $\mathrm{BD}-\mathrm{of}$ the as-built 316LSS produced at the different laser powers. The presence of these irregularly shaped pores at the melt pool boundaries can be seen in Figure 8a, along with some indication of balling behavior due to the insufficient melting of the 316LSS powder at the low applied laser power $(160 \mathrm{~W})$ and infill $\mathrm{E}_{\text {density }}$ $\left(38.1 \mathrm{~J} \cdot \mathrm{mm}^{-3}\right)$. The presence of such defects can be mainly attributed to insufficient bonding between the layers and/or scan tracks due to the low penetration of the laser energy [7], which results in a smaller melt pool size that leaves some powder particles un-melted or semi-melted in the $160 \mathrm{~W}$ sample. Similarly, insufficient energy during the powder bed processing of other metals, including maraging steels [50], as well as titanium and aluminum alloys [51-53], has also been noted to lead to melt pool discontinuities, which result in a lack of fusion defects, consisting of pores with irregular morphologies and un-/semi-melted powders.

By contrast, the 3D macrostructures of the 316LSS samples produced at $240 \mathrm{~W}$ (Figure 8b), $320 \mathrm{~W}$ (Figure $8 \mathrm{c}$ ), and $380 \mathrm{~W}$ (Figure 8d) revealed no cracking and a very limited number of small, isolated pores with spherical morphologies. Typically, such non-uniformly distributed spherical pores in the microstructure of 316LSS have been reported as unavoidable gas-induced porosity originating from gas entrapment in the powder feedstock [54], as well as solidification shrinkage [55].

Material addition layer-upon-layer during the LPB process resulted in a macrostructure composed of overlapping scanning tracks of the laser beam, as illustrated by the optical microscopy images in Figure 8 of the etched 316LSS samples. In particular, the rastering scan pattern and the layer-by-layer rotation (at an angle of $90^{\circ}$ ) applied during LPB processing were especially evident in the $\mathrm{X}-\mathrm{Y}$ planes of the near-full-density 316LSS samples, as revealed in Figure $8 \mathrm{~b}-\mathrm{d}$. For the sample produced at $240 \mathrm{~W}$ (infill $\mathrm{E}_{\mathrm{density}}$ of $57.1 \mathrm{~J} \cdot \mathrm{mm}^{-3}$ ), the average width of the scan tracks was $\sim 94 \mu \mathrm{m}$. With increasing laser power and $E_{\text {density, }}$, the average width of the scan tracks increased roughly to $100 \mu \mathrm{m}$ at $320 \mathrm{~W}\left(76.2 \mathrm{~J} \cdot \mathrm{mm}^{-3}\right)$ and $195 \mu \mathrm{m}$ at $380 \mathrm{~W}\left(90.5 \mathrm{~J} \cdot \mathrm{mm}^{-3}\right)$. By contrast, the cross-sections of these melted scan tracks appeared as curved "troughs", and both the $\mathrm{X}-\mathrm{Z}$ and $\mathrm{Y}-\mathrm{Z}$ planes in the near-full density 316LSS samples showed overlapping patterns of half-ellipse-shaped 
molten pool boundaries, as displayed in Figure $8 \mathrm{~b}-\mathrm{d}$. For the $240 \mathrm{~W}$ sample, the melt pool beads were $\sim 135 \mu \mathrm{m}$ in width and $\sim 128 \mu \mathrm{m}$ in depth. With increasing laser power, the average dimensions of the melt pool beads increased in width to $148 \mu \mathrm{m}$ and $162 \mu \mathrm{m}$ for the $320 \mathrm{~W}$ and $380 \mathrm{~W}$ samples, respectively, but the aspect ratio remained similar. This agrees with reported studies on the LPB processing of steels that showed increasing bead width with increasing laser power $[56,57]$ and was attributed to the dependence of the melt pool dimensions on the LPB process parameters, including the $E_{\text {density }}, d, h_{L}, h_{S}$, etc. [58].
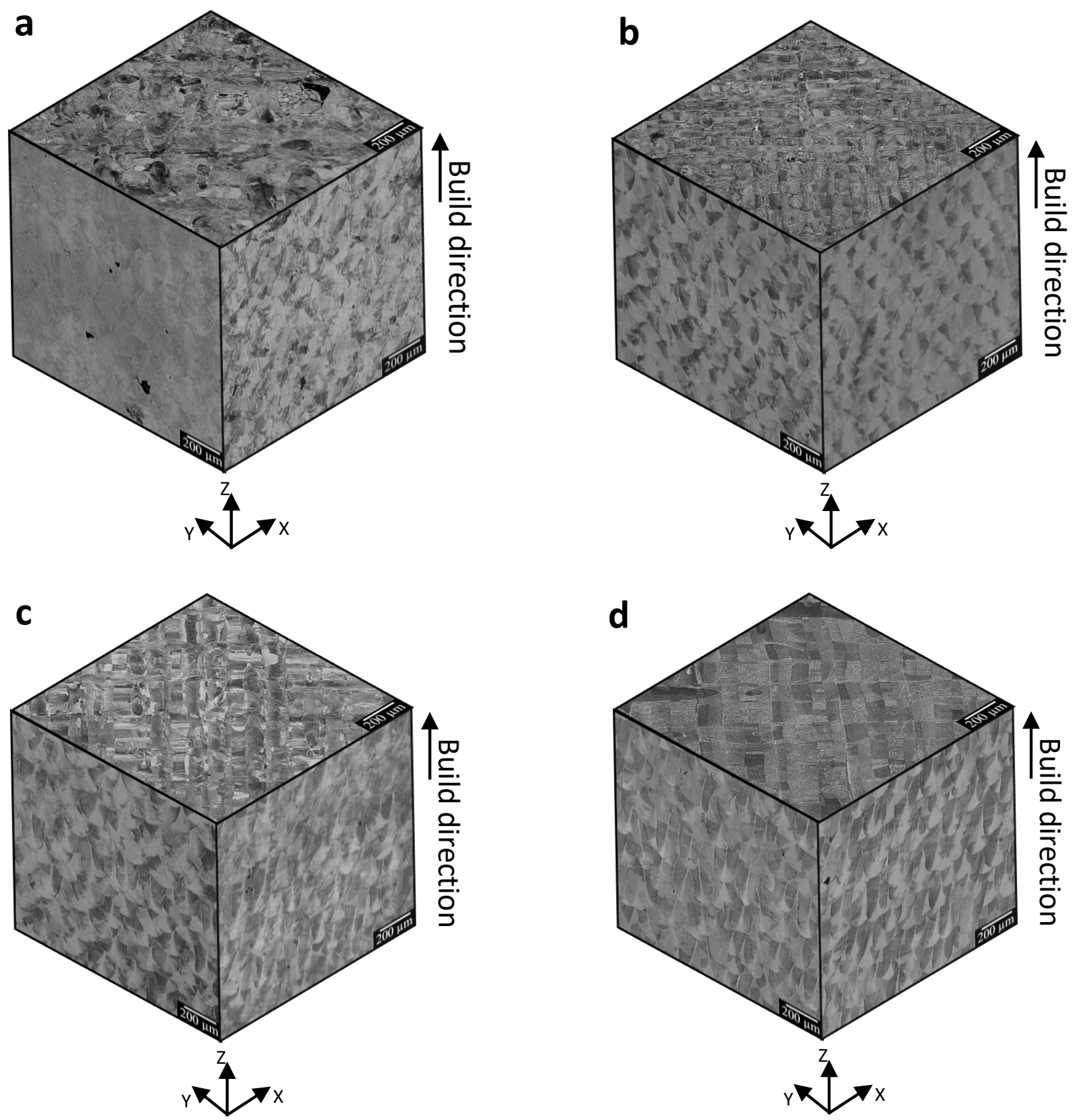

Figure 8. Representative optical microscopy images on the 3 orthogonal planes after etching the as-built 316LSS produced at (a) $160 \mathrm{~W}$, (b) $240 \mathrm{~W}$, (c) $320 \mathrm{~W}$, and (d) $380 \mathrm{~W}$.

At higher magnification, the visible molten pool boundaries showed good metallurgical bonding without the presence of any microvoids and/or microcracking. A fine cellular solidification structure was observed within the individual molten pools, as shown in Figure 9a,b for the BD and TD of the as-built 316LSS. These solidification cells were 
inhomogeneous in size and orientation and their growth was confined within the molten pool boundaries. In the 316LSS samples, the different remnant cells within the epitaxially grown grains had an average spacing of $\sim 0.58 \mu \mathrm{m}$. Similar fine cellular structures have been reported for 316LSS produced additively, and attributed to the rapid solidification of the molten pool due to the high cooling rates (on the order of $10^{3}-10^{8} \mathrm{~K} \cdot \mathrm{s}^{-1}$ ) in the LPB process $[59,60]$.
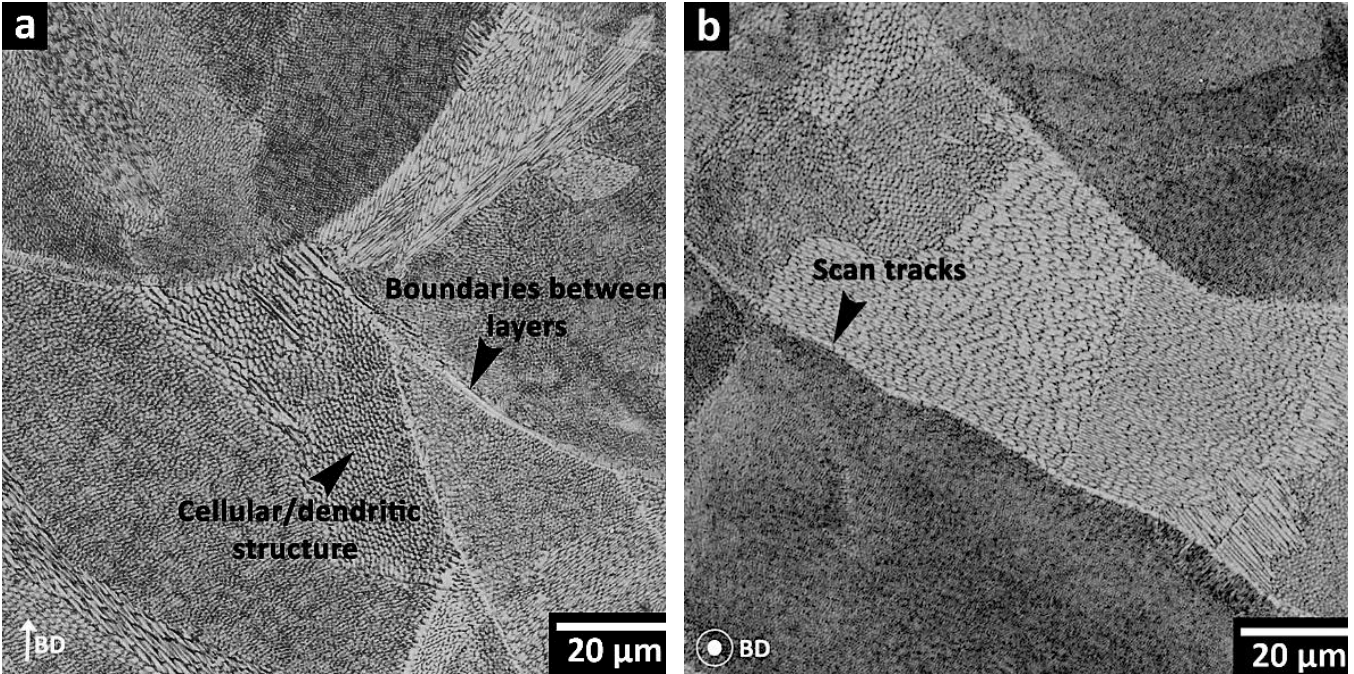

Figure 9. Representative optical microscopy images in as-built 316LSS (a) along the BD and (b) normal to the $\mathrm{BD}$ (TD).

The phase analysis of the 316LSS samples indicated that the primary solidification phase was face-centered cubic $\gamma$-austenite without any detectable presence of $\delta$-ferrite, as indicated by the representative XRD patterns given in Figure 10a. A similar result was obtained through the measurement of the $\delta$-ferrite content using a Feritscope, with average readings between $0.13 \%$ and $0.17 \%$ that were at the detection limits of this method and indicate a predominant austenitic structure. Considering the equivalent $\mathrm{Cr} / \mathrm{Ni}$ ratio (1.38) and a solidification rate of $\sim 20 \mathrm{~mm} \cdot \mathrm{s}^{-1}$ obtained from the Kurz-Giovanola-Trivedi (KGT) model of 316LSS, using the measured average cell size of $\sim 0.58 \mu \mathrm{m}$, the dominant phases can be predicted using the solidification map reported in the literature [61]. Figure 10b shows that the samples used in this study are well into the fully austenitic region, further supporting the XRD and Feritscope results. Many studies on the LPB processing of 316LSS have observed a predominant austenitic structure [5,7,11,62-64], but some have also reported small amounts of $\delta$-ferrite or $\alpha^{\prime}$-martensite [65-67]. The rapid solidification of the molten pool due to the high cooling rates has been reported to favor the formation of $\gamma$-austenite [68], while slow cooling rates (as a result of thermal cycling, for example) tend to promote $\delta$-ferrite stabilization, especially in micro-segregated regions $[69,70]$. 

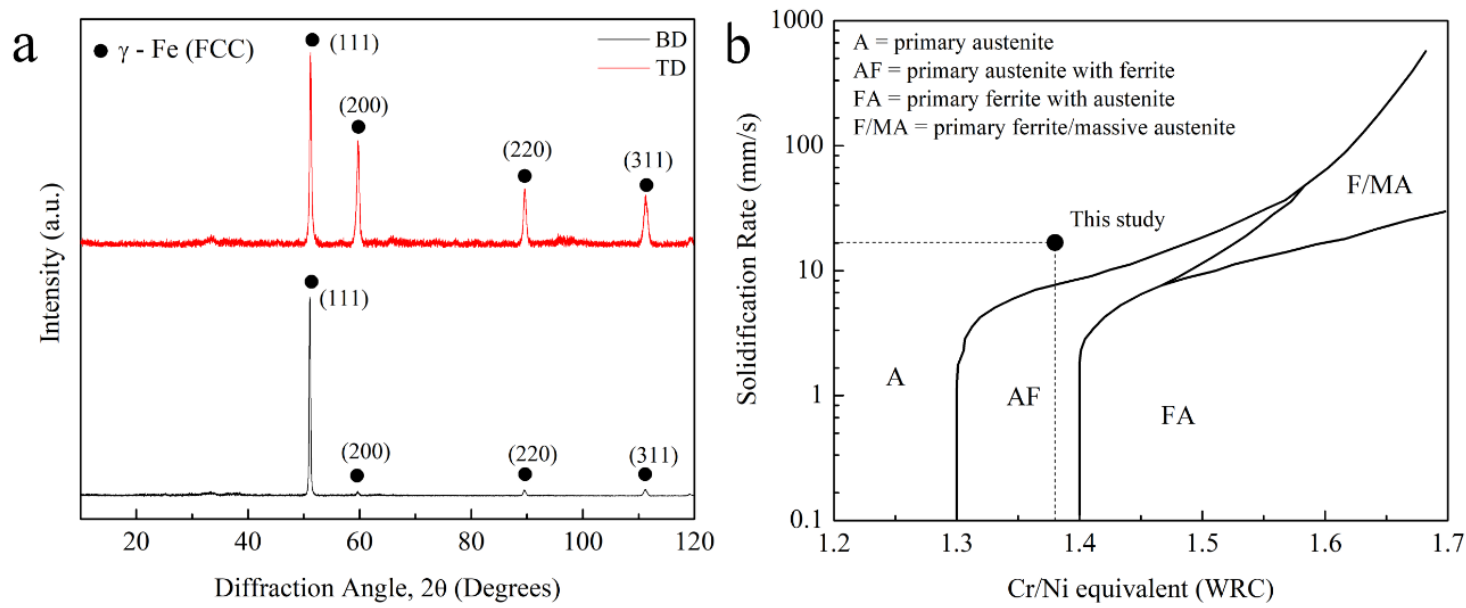

Figure 10. Representative XRD patterns of the 316LSS samples were produced using LPB A/SM (a). (b) Solidification map for austenitic stainless-steel welds [61].

\subsection{Mechanical Properties}

Using the Rockwell C-scale and Vickers methods, the bulk hardness and microhardness of the 316LSS were measured for the different laser power (and infill $\mathrm{E}_{\text {density }}$ ) conditions, as given in Table 3. The average hardness of the 316LSS was lowest (11.0 $\pm 0.5 \mathrm{HRC}$ and $\left.206.9 \pm 17.0 \mathrm{HV}_{0.5}\right)$ for the lowest applied laser power of $160 \mathrm{~W}$ (infill $\mathrm{E}_{\text {density }}=38.1 \mathrm{~J} \cdot \mathrm{mm}^{-3}$ ), which exhibited the lowest densities of $7.84 \mathrm{~g} \cdot \mathrm{cm}^{3}$ (Archimedes) and $7.97 \mathrm{~g} \cdot \mathrm{cm}^{3}$ (gas pycnometry) or highest porosity percentage values of $0.4 \%$ (gas pycnometry) and $2 \%$ (Archimedes). In addition, the measured Vickers hardness of $207.1 \pm 17.6 \mathrm{HV}_{0.5}$ in the TD and $206.6 \pm 16.3 \mathrm{HV}_{0.5}$ in the BD indicated insignificant anisotropy in the hardness of 316LSS (with the lowest $p$-value of 0.9958). However, the microhardness plotted across the sample cross-section (Figure 11) indicated considerable scatter in the data for the $160 \mathrm{~W}$ laser power that could be attributed to the distributed defects in the 316LSS structure (Figures 6a and 8a). Specifically, the local hardness near any large inter-layer and/or interconnected pores $\left(186.2 \mathrm{HV}_{0.5}\right)$ was lower by $16 \%$ relative to the remaining locations $\left(221.3 \mathrm{HV}_{0.5}\right)$ in the $316 \mathrm{LSS}$. Thus, improved densification (to near-full density) at the higher laser powers of $240 \mathrm{~W}$ (infill $\mathrm{E}_{\text {density }}=57.1 \mathrm{~J} \cdot \mathrm{mm}^{-3}$ ), $320 \mathrm{~W}$ (infill $\mathrm{E}_{\text {density }}=76.2 \mathrm{~J} \cdot \mathrm{mm}^{-3}$ ), and $380 \mathrm{~W}$ (infill $\mathrm{E}_{\text {density }}=90.5 \mathrm{~J} \cdot \mathrm{mm}^{-3}$ ) resulted in an increase of more than $30 \%$ in the average Rockwell C hardness and $9 \%$ in the average Vickers microhardness relative to the $160 \mathrm{~W}$ condition. In the range of $240 \mathrm{~W}$ to $380 \mathrm{~W}$, the influence of the laser power on the hardness was not obvious, as the bulk hardness increased from 14.2 to $17.9 \mathrm{HRC}$, while the Vickers microhardness was statistically comparable (from a t-test with an alpha level of 0.05 ) within the narrow range of $226.1 \mathrm{HV}_{0.5}$ to $235.6 \mathrm{HV}_{0.5}$.

Table 3. Average hardness values of as-built 316LSS.

\begin{tabular}{|c|c|c|c|c|c|c|c|}
\hline $\begin{array}{l}\text { Laser Power } \\
\text { (W) }\end{array}$ & $\begin{array}{c}\text { Infill } \mathrm{E}_{\text {density }} \\
\left(\mathrm{J} / \mathrm{mm}^{3}\right)\end{array}$ & $\begin{array}{c}\text { Rockwell } \\
\text { Hardness (HRC) }\end{array}$ & STD & $\begin{array}{c}\text { Vickers } \\
\text { Microhardness in } \\
\text { TD }\left(\mathrm{HV}_{0.5}\right)\end{array}$ & STD & $\begin{array}{c}\text { Vickers } \\
\text { Microhardness in } \\
\text { BD }\left(\mathrm{HV}_{0.5}\right)\end{array}$ & STD \\
\hline 160 & 38.1 & 11.0 & 0.5 & 207.1 & 17.6 & 206.6 & 16.3 \\
\hline 240 & 57.1 & 14.2 & 0.8 & 229.6 & 3.0 & 231.2 & 4.0 \\
\hline 320 & 76.2 & 16.5 & 0.6 & 226.1 & 3.1 & 227.8 & 3.7 \\
\hline 380 & 90.5 & 17.9 & 1.1 & 235.6 & 2.4 & 234.7 & 3.1 \\
\hline
\end{tabular}


a

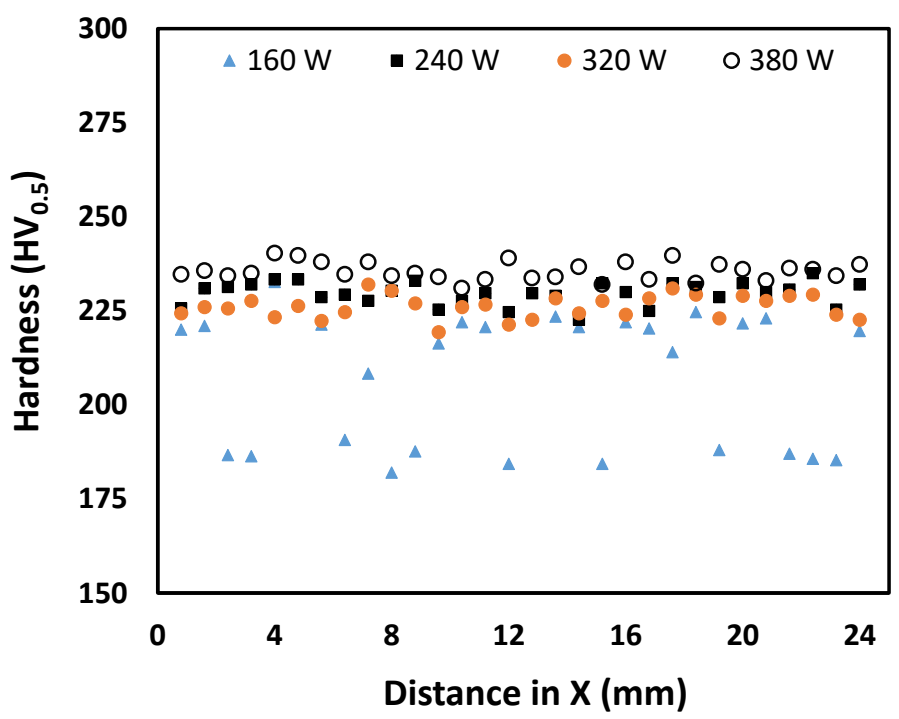

b

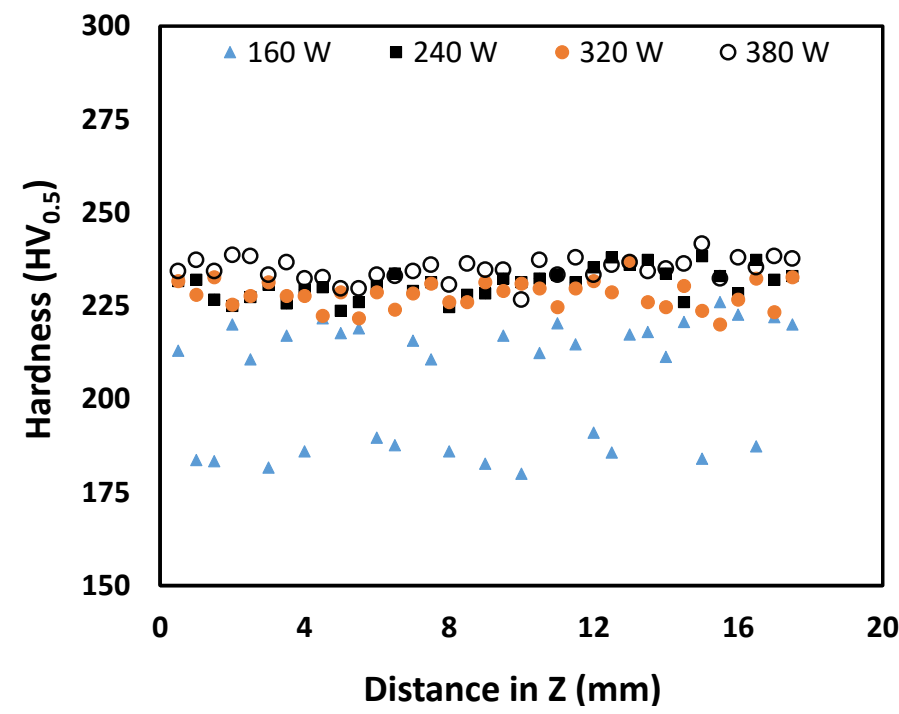

Figure 11. Variation in the microhardness of as-built 316LSS produced at different laser powers: (a) TD and (b) BD.

To analyze these measured data against benchmark values for conventionally manufactured 316LSS, the stipulations in relevant ASTM standards were examined, as given in Table 4. For instance, the maximum hardness of $95 \mathrm{HRB}$ (or $18 \mathrm{HRC}$ ), as specified in both ASTM A240-20a [71] and ASTM A666-15 [72] for 316LSS, has been specified to ensure the adequate efficacy of the solution annealing heat treatment to reduce excess hardness from cold working, to dissolve carbide precipitates, and/or fully transform any retained (high hardness) $\delta$-ferrite to austenite within the through-thickness of wrought products. Representative values for hot-rolled (75.8 HRB) and annealed (73.2 HRB) 316LSS, as reported by Song et al. [73], are consistent with these ASTM standards and point to the highest hardness possible when processing 316LSS additively. However, for CF3M, the cast equivalent of wrought 316LSS, ASTM A743-21 [74], does not stipulate any hardness maximum, but a value of $179 \mathrm{HB}(\sim 89 \mathrm{HRB}$ or $\sim 10 \mathrm{HRC})$ after solution annealing was reported in [75]. Similarly, for additively manufactured 316LSS by powder bed processing (laser or electron beam), no requirements for hardness are specified in ASTM F3184-16 [76], but values between 76.5 HRB [77] and 25.5 HRC [78,79] have been reported and support 
reasonably the bulk hardness values measured in the present study. These higher hardness values measured for 316LSS manufactured additively (relative to castings, for example) have been linked to the fineness of the cellular microstructure (Figure 9) that results from the rapid cooling conditions during LPB processing [68].

Table 4. Specification of the mechanical properties of 316LSS in ASTM standards.

\begin{tabular}{cccccc}
\hline & $\begin{array}{c}\text { Rockwell } \\
\text { (HRB) }\end{array}$ & $\begin{array}{c}\text { Rockwell } \\
\text { (HRC) }^{\mathbf{a}}\end{array}$ & YS (MPa) & UTS (MPa) & EL (\%) \\
\hline ASTM A240-20 a & $\leq 95$ & 18 & $\geq 170$ & $\geq 485$ & $\geq 40$ \\
Annealed [71] & $\leq 95$ & 18 & $\geq 170$ & $\geq 485$ & $\geq 40$ \\
ASTM A666-15 Annealed [72] & $\mathrm{N} / \mathrm{A}$ & 10 & $\geq 205$ & $\geq 485$ & $\geq 30$ \\
ASTM A743-21 & $\mathrm{N} / \mathrm{A}$ & $\mathrm{N} / \mathrm{A}$ & $\geq 205$ & $\geq 515$ & $\geq 30$ \\
$\begin{array}{l}\text { Cast CF3M [74,75] } \\
\text { ASTM F3184-16 }\end{array}$ & & &
\end{tabular}

Also, several studies have examined the microhardness of as-built 316LSS to understand the effect of anisotropy, process parameters, and density. For instance, Kamariah et al. [80] investigated different orientations $\left(0^{\circ}, 45^{\circ}\right.$, and $\left.90^{\circ}\right)$ in 316LSS produced by selective laser melting (SLM) using a layer thickness of $30 \mu \mathrm{m}$ on an SLM 125 HL system and reported comparably similar microhardness values, ranging from $209 \mathrm{HV}_{0.5}$ to $212 \mathrm{HV}_{0.5}$, which indicated low anisotropy in the as-built condition. Tolosa et al. [81] also explored the effect of the material anisotropy and oriented the built samples (SLM 250 Realizer) in every possible direction to examine the impact on mechanical properties; though the individual values ranged from $215 \mathrm{HV}$ to $255 \mathrm{HV}$, no trend with orientation was identified and a mean value of $235 \mathrm{HV}$ was reported. Cherry et al. [8] analyzed the effect of $\mathrm{E}_{\text {density }}$ on the porosity and hardness of 316LSS produced on a Renishaw AM250 system and reported increasing hardness with decreasing porosity until a maximum of $225 \mathrm{HV}_{10}$ at $125 \mathrm{~J} \cdot \mathrm{mm}^{-3}$. Sun et al. [82] investigated the influence of $v$ and $\mathrm{h}_{\mathrm{S}}$ on the SLM (250 HL) of 316LSS at a fixed $\mathrm{E}_{\text {density }}\left(\sim 104.5 \mathrm{~J} \cdot \mathrm{mm}^{-3}\right)$ with an $\mathrm{h}_{\mathrm{L}}$ of $50 \mu \mathrm{m}$. The microhardness of their as-built near-full-density parts was between $213 \mathrm{HV}_{1}$ and $220 \mathrm{HV}_{1}$. The research of Tucho et al. [65] showed strong influences of $E_{\text {density }}$ on the porosity and they reported the lowest $\left(176 \pm 9 \mathrm{HV}_{5}\right)$ and highest $\left(213 \pm 3 \mathrm{HV}_{5}\right)$ hardness values for the 316LSS produced (using SLM $280 \mathrm{HL}$ ) at $50 \mathrm{~J} \cdot \mathrm{mm}^{-3}$ and $80 \mathrm{~J} \cdot \mathrm{mm}^{-3}$, respectively. Recently, Eliasu et al. [83] investigated the AM of 316LSS on an EOS M280 system $\left(\mathrm{h}_{\mathrm{L}}=30 \mu \mathrm{m}\right)$ by varying the $\mathrm{E}_{\text {density }}$ from 20.4 to $142.9 \mathrm{~J} \cdot \mathrm{mm}^{-3}$ to examine the influence of porosity on hardness and reported maximum values ranging from $230 \mathrm{HV}_{0.3}$ to $240 \mathrm{HV}_{0.3}$ for the highest relative densities (91-93\%) realized between 44.44 and $111.11 \mathrm{~J} \cdot \mathrm{mm}^{-3}$. Thus, the role of the $\mathrm{E}_{\text {density }}$ on the part density and, in turn, the hardness of 316LSS that was observed in the present study, concurs reasonably well with previously reported findings for SLM and LPB processes. Furthermore, the similar Vickers hardness of near-full-density 316LSS (226.1 $\mathrm{HV}_{0.5}$ to $\left.235.6 \mathrm{HV}_{0.5}\right)$ in the TD and $\left(227.8 \mathrm{HV}_{0.5}\right.$ to $\left.234.7 \mathrm{HV}_{0.5}\right)$ in the $\mathrm{BD}$ produced by $\mathrm{A} / \mathrm{SM}$ with the Matsuura LUMEX Avance-25 technology also agrees with the values and low anisotropy reported for the stand-alone LPB AM of 316LSS, as tabulated in Table 5. One noteworthy exception is the reported highest value by Saeidi et al. [64] of $325 \mathrm{HV}_{1}$, which was attributed to a fine cellular size and high amounts of amorphous nano-scale silicate inclusions in their 316LSS builds $[84,85]$. 
Table 5. As-built, room temperature properties of 316LSS using stand-alone LPB AM.

\begin{tabular}{|c|c|c|c|c|c|}
\hline AM Systems & Hardness & YS (MPa) & UTS (MPa) & EL (\%) & YM (GPa) \\
\hline $\begin{array}{c}\text { Renishaw, } \mathrm{h}_{\mathrm{L}}-50 \mu \mathrm{m} \\
\text { Datasheet [86] }\end{array}$ & $\begin{array}{l}198 \pm 8 \mathrm{HV}_{0.5}(\mathrm{H}) \\
208 \pm 6 \mathrm{HV}_{0.5}(\mathrm{~V})\end{array}$ & $\begin{array}{l}547 \pm 3(\mathrm{H}) \\
494 \pm 14(\mathrm{~V})\end{array}$ & $\begin{array}{r}676 \pm 2(\mathrm{H}) \\
624 \pm 17(\mathrm{~V}) \\
\end{array}$ & $\begin{array}{l}43 \pm 2(\mathrm{H}) \\
35 \pm 8(\mathrm{~V})\end{array}$ & $\begin{array}{c}197 \pm 4(\mathrm{H}) \\
190 \pm 10(\mathrm{~V})\end{array}$ \\
\hline $\begin{array}{c}\text { Renishaw AM250, } \\
\mathrm{h}_{\mathrm{L}}-50 \mu \mathrm{m}[56]\end{array}$ & $\begin{array}{c}228 \pm 4 \mathrm{HV}_{1}(\mathrm{H}) \\
219-239 \pm 5 \mathrm{HV}_{1}(\mathrm{~V})\end{array}$ & $487 \pm 3(\mathrm{~V})$ & $594 \pm 4(\mathrm{~V})$ & $49 \pm 4(\mathrm{~V})$ & \\
\hline $\begin{array}{c}\text { Renishaw AM250, } \\
h_{L}-50 \mu \mathrm{m}[59]\end{array}$ & & $\begin{array}{c}554 \pm 5(\mathrm{H}) \\
\mathrm{N} / \mathrm{A}(\mathrm{V})\end{array}$ & $\begin{array}{r}685 \pm 5(\mathrm{H}) \\
581 \pm 14(\mathrm{~V})\end{array}$ & $\begin{array}{l}36.3 \pm 2.2(\mathrm{H}) \\
25.7 \pm 12.2(\mathrm{~V})\end{array}$ & \\
\hline $\begin{array}{c}\text { Renishaw AM125, } \\
\mathrm{h}_{\mathrm{L}}-50 \mu \mathrm{m}[87]\end{array}$ & $215 \pm 10 \mathrm{HV}_{1}(\mathrm{H})$ & $539 \pm 3(\mathrm{H})$ & $600 \pm 3(\mathrm{H})$ & $28 \pm 0.5(\mathrm{H})$ & \\
\hline $\begin{array}{l}\text { EOS M100, } \mathrm{h}_{\mathrm{L}}-20 \mu \mathrm{m} \\
\text { Flexline [88] }\end{array}$ & $\mathrm{N} / \mathrm{A}$ & $\begin{array}{l}535(\mathrm{H}) \\
490(\mathrm{~V})\end{array}$ & $\begin{array}{l}650(\mathrm{H}) \\
590(\mathrm{~V})\end{array}$ & $\begin{array}{l}35(\mathrm{H}) \\
45(\mathrm{~V})\end{array}$ & \\
\hline $\begin{array}{l}\text { EOSINT M280, } \\
\mathrm{h}_{\mathrm{L}}-20 \mu \mathrm{m}[89]\end{array}$ & 85 HRB & $\begin{array}{l}530 \pm 60(\mathrm{H}) \\
470 \pm 90(\mathrm{~V})\end{array}$ & $\begin{array}{l}640 \pm 50(\mathrm{H}) \\
540 \pm 55(\mathrm{~V})\end{array}$ & $\begin{array}{l}40 \pm 15(\mathrm{H}) \\
50 \pm 20(\mathrm{~V})\end{array}$ & $\begin{array}{l}185(\mathrm{H}) \\
180(\mathrm{~V})\end{array}$ \\
\hline $\begin{array}{l}\text { EOS M290, TRL } 8 \\
h_{L}-20 \mu \mathrm{m}[89,90]\end{array}$ & & $\begin{array}{l}530 \pm 20(\mathrm{H}) \\
470 \pm 30(\mathrm{~V})\end{array}$ & $\begin{array}{l}640 \pm 20(\mathrm{H}) \\
540 \pm 30(\mathrm{~V})\end{array}$ & $\begin{array}{l}40 \pm 2(\mathrm{H}) \\
54 \pm 7(\mathrm{~V})\end{array}$ & \\
\hline $\begin{array}{c}\text { EOS M290, TRL 7 } \\
\text { FlexLine, } \mathrm{h}_{\mathrm{L}}-40 \mu \mathrm{m}[90]\end{array}$ & & $\begin{array}{l}540 \pm 50(\mathrm{H}) \\
480 \pm 40(\mathrm{~V})\end{array}$ & $\begin{array}{l}640 \pm 50(\mathrm{H}) \\
570 \pm 40(\mathrm{~V})\end{array}$ & $\begin{array}{l}40 \pm 3(\mathrm{H}) \\
51 \pm 9(\mathrm{~V})\end{array}$ & \\
\hline $\begin{array}{c}\text { EOS M400-4, TRL } 7 \\
\text { FlexLine, } \\
\mathrm{h}_{\mathrm{L}}-40 \mu \mathrm{m}[90,91]\end{array}$ & $90 \mathrm{HRB}$ & $\begin{array}{l}550 \pm 10(\mathrm{H}) \\
490 \pm 10(\mathrm{~V})\end{array}$ & $\begin{array}{l}650 \pm 10(\mathrm{H}) \\
590 \pm 10(\mathrm{~V})\end{array}$ & $\begin{array}{l}40 \pm 2(\mathrm{H}) \\
45 \pm 8(\mathrm{~V})\end{array}$ & \\
\hline EOS M270, $\mathrm{h}_{\mathrm{L}}-20 \mu \mathrm{m}[64]$ & $325 \mathrm{HV}_{1}$ & $456 \pm 17$ & $703 \pm 8$ & $\sim 48$ & \\
\hline $\begin{array}{c}\text { EOS M270, } \\
\mathrm{h}_{\mathrm{L}}-20 \mu \mathrm{m}[92]\end{array}$ & & $\begin{array}{c}493 \pm 11(\mathrm{H}) \\
480 \pm 13\left(45^{\circ}\right) \\
409 \pm 26(\mathrm{~V})\end{array}$ & $\begin{array}{c}636 \pm 15(\mathrm{H}) \\
647 \pm 11\left(45^{\circ}\right) \\
564 \pm 17(\mathrm{~V})\end{array}$ & $\begin{array}{c}35.1 \pm 5.0(\mathrm{H}) \\
55.8 \pm 3.0\left(45^{\circ}\right) \\
39.2 \pm 15.8(\mathrm{~V})\end{array}$ & \\
\hline EOS M290 [93] & & $\sim 625(\mathrm{H})$ & $\sim 750(\mathrm{H})$ & $\sim 54 \%(\mathrm{H})$ & \\
\hline $\begin{array}{l}\text { SLM Solutions, } \\
\mathrm{h}_{\mathrm{L}}-50 \mu \mathrm{m}[94]\end{array}$ & $209 \pm 2 \mathrm{HV}_{10}$ & $519 \pm 25$ & $633 \pm 28$ & $31 \pm 6$ & $184 \pm 20$ \\
\hline $\begin{array}{c}\text { SLM Solutions } \\
125 \mathrm{HL}, \mathrm{h}_{\mathrm{L}}-30 \mu \mathrm{m}[62]\end{array}$ & $\sim 229 \mathrm{HV}_{3}(\mathrm{H})$ & $\sim 490 \pm 5$ & $\sim 640 \pm 10$ & $\sim 25 \pm 2$ & \\
\hline $\begin{array}{l}\text { SLM } 250 \text { Realizer, } \\
\mathrm{h}_{\mathrm{L}}-30 \mu \mathrm{m} \text { [81] }\end{array}$ & 215-255 HV & $\begin{array}{l}669 \pm 12(\mathrm{H}) \\
540 \pm 11(\mathrm{~V})\end{array}$ & $\begin{array}{l}687 \pm 11(\mathrm{H}) \\
582 \pm 11(\mathrm{~V})\end{array}$ & $\begin{array}{l}30.0 \pm 2.9(\mathrm{H}) \\
43.4 \pm 1.5(\mathrm{~V})\end{array}$ & \\
\hline $\begin{array}{l}\text { SLM } 250 \text { Realizer, } \\
\mathrm{h}_{\mathrm{L}}-60 \mu \mathrm{m} \text { [95] }\end{array}$ & & $\begin{array}{l}534 \pm 5.7\left(\mathrm{H}_{\mathrm{x}}\right) \\
528 \pm 3.9\left(\mathrm{H}_{\mathrm{y}}\right) \\
444 \pm 26.5(\mathrm{~V}) \\
\end{array}$ & $\begin{array}{l}653 \pm 3.4\left(\mathrm{H}_{\mathrm{x}}\right) \\
659 \pm 3.2\left(\mathrm{H}_{\mathrm{y}}\right) \\
567 \pm 18.6(\mathrm{~V}) \\
\end{array}$ & $\begin{array}{c}16.2 \pm 0.8 *\left(\mathrm{H}_{\mathrm{x}}\right) \\
16.6 \pm 0.4^{*}\left(\mathrm{H}_{\mathrm{y}}\right) \\
8 \pm 2.9 *(\mathrm{~V})\end{array}$ & \\
\hline $\begin{array}{c}\text { SLM Solutions } \\
280 \mathrm{HL}, \mathrm{h}_{\mathrm{L}}-30 \mu \mathrm{m}[96]\end{array}$ & 223-245 $\mathrm{HV}_{30}(\mathrm{H}, \mathrm{V})$ & $\begin{array}{c}528 \pm 5(\mathrm{H}) \\
439 \pm 10(\mathrm{~V}) \\
590 \pm 12\left(45^{\circ}\right) \\
\end{array}$ & $\begin{array}{c}639 \pm 5(\mathrm{H}) \\
512 \pm 18(\mathrm{~V}) \\
699 \pm 23\left(45^{\circ}\right) \\
\end{array}$ & $\begin{array}{c}38.0 \pm 0.7(\mathrm{H}) \\
11.8 \pm 5.4(\mathrm{~V}) \\
32.6 \pm 10.2\left(45^{\circ}\right) \\
\end{array}$ & $\begin{array}{c}179 \pm 25(\mathrm{H}) \\
138 \pm 14(\mathrm{~V}) \\
227 \pm 25\left(45^{\circ}\right) \\
\end{array}$ \\
\hline $\begin{array}{l}\text { Concept Laser } \\
\text { Datasheet [97] }\end{array}$ & $20 \mathrm{HRC}$ & $\begin{array}{c}374 \pm 5(\mathrm{~V}) \\
385 \pm 6\left(45^{\circ}\right) \\
330 \pm 8(\mathrm{H}) \\
\end{array}$ & $\begin{array}{c}650 \pm 5(\mathrm{~V}) \\
640 \pm 7\left(45^{\circ}\right) \\
529 \pm 8(\mathrm{H}) \\
\end{array}$ & $\begin{array}{c}65 \pm 4(\mathrm{~V}) \\
63 \pm 5\left(45^{\circ}\right) \\
63 \pm 5(\mathrm{H})\end{array}$ & \\
\hline $\begin{array}{l}\text { Concept Laser } \\
\text { Mlab-Cusing, } \\
\mathrm{h}_{\mathrm{L}}-25 \mu \mathrm{m}[7]\end{array}$ & $240 \mathrm{HV}_{0.5}(\mathrm{H})$ & $532 \pm 3(\mathrm{H})$ & $573 \pm 6(\mathrm{H})$ & $41 \pm 1.4(\mathrm{H})$ & \\
\hline \multirow{4}{*}{$\begin{array}{l}\text { Concept Laser } \\
\text { Mlab-Cusing, } \\
\mathrm{h}_{\mathrm{L}}-30 \mu \mathrm{m}[60]\end{array}$} & \multirow{4}{*}{$\mathrm{N} / \mathrm{A}$} & $512 \pm 14(\mathrm{SM}-\mathrm{V})$ & $62 \pm 12(\mathrm{SM}-\mathrm{V})$ & $20.4 \pm 3(\mathrm{SM}-\mathrm{V})$ & \\
\hline & & $430 \pm 11(\mathrm{SM}-\mathrm{H})$ & $509 \pm 3(\mathrm{SM}-\mathrm{H})$ & $12.4 \pm 1(\mathrm{SM}-\mathrm{H})$ & \\
\hline & & $536 \pm 4(\mathrm{CB}-\mathrm{V})$ & $668 \pm 5(\mathrm{CB}-\mathrm{V})$ & $24.7 \pm 2(\mathrm{CB}-\mathrm{V})$ & \\
\hline & & $448 \pm 20(\mathrm{CB}-\mathrm{H})$ & $528 \pm 7(\mathrm{CB}-\mathrm{H})$ & $11.6 \pm 1(\mathrm{CB}-\mathrm{H})$ & \\
\hline Concept Laser M2 [98] & & $590 \pm 5(\mathrm{~V})$ & $700(\mathrm{~V})$ & $\sim 59 \%(\mathrm{~V})$ & \\
\hline $\begin{array}{l}\text { Fraunhofer open } \\
\text { architecture [98] }\end{array}$ & & $450 \pm 10(\mathrm{~V}, \mathrm{H})$ & $640(\mathrm{~V}, \mathrm{H})$ & $\sim 87 \%(\mathrm{~V}, \mathrm{H})$ & \\
\hline Sisma MYSINT100 [63] & 210-240 HV 1 & $\begin{array}{l}\sim 505-525\left(45^{\circ}\right) \\
\sim 430-495(\mathrm{~V}) \\
\end{array}$ & $\begin{aligned} & \sim 650\left(45^{\circ}\right) \\
& \sim 550-575(\mathrm{~V})\end{aligned}$ & $\begin{aligned} & \sim 40\left(45^{\circ}\right) \\
& \sim 66-72(\mathrm{~V})\end{aligned}$ & \\
\hline $\begin{array}{l}\text { SYNDAYA Dimetal-100, } \\
\mathrm{h}_{\mathrm{L}}-30 \mu \mathrm{m}[66]\end{array}$ & $281.6 \mathrm{HV}_{0.1}$ & & $\sim 590(\mathrm{H})$ & $\sim 21.1(\mathrm{H})$ & \\
\hline
\end{tabular}

$\mathrm{SM}=$ Single-melt laser scanning; $\mathrm{CB}=$ checker board laser scanning; $\mathrm{TRL}=$ Technology readiness level; $\mathrm{V}=\mathrm{Vertical}$ and $\mathrm{H}=$ Horizontal samples/direction. ${ }^{*}$ Uniform percent elongation. 
The nominal engineering stress-strain curves of the as-built 316LSS tensile samples, as given in Figure 12, were analyzed to evaluate the mechanical properties-namely YS, UTS, EL, and YM-for the four laser powers (Table 6). The mechanical response of the as-built 316LSS produced at $160 \mathrm{~W}$ consisted of a linear elastic region characterized by a YM of $175.1 \pm 10.4 \mathrm{GPa}$ with the onset of early yielding at $493.8 \pm 10.5 \mathrm{MPa}$, which was followed by limited plastic deformation to a maximum stress (UTS) of $603.9 \pm 9.0 \mathrm{MPa}$ with premature failure occurring before necking at a total EL (strain) of 17.3\%. The observed premature failure of the 316LSS built at $160 \mathrm{~W}$ may be attributed to its low relative density (98\%) and characteristics of the internal defects, namely the lack of fusion layers with large interconnected and irregular pores that can act as initiation sites for crack formation and subsequent propagation through the microstructure. The high degree of these defects (as seen in Figures $6 \mathrm{a}$ and $8 \mathrm{a}$ ) thus played a crucial role in limiting the mechanical performance of the 316LSS built at $160 \mathrm{~W}$, as corroborated by the lower YS (by 10\%), UTS (by 16\%), YM (by $\sim 21 \%$ ), and EL (by $\sim 70 \%$ ), relative to the $240 \mathrm{~W}$ condition.

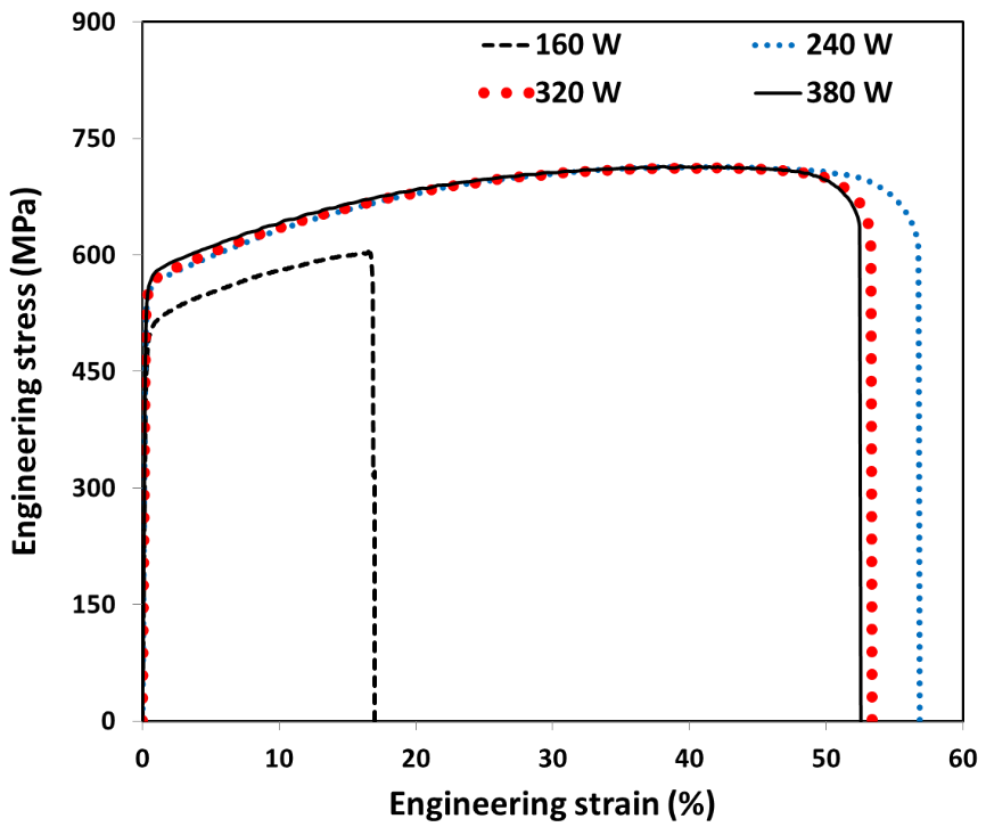

Figure 12. Average tensile stress-strain curves for as-built 316LSS produced at laser powers of $160 \mathrm{~W}$, $240 \mathrm{~W}, 320 \mathrm{~W}$, and $380 \mathrm{~W}$.

Table 6. Average as-built static tensile properties of 316LSS.

\begin{tabular}{cccccccccc}
\hline Power $(\mathbf{W})$ & $\begin{array}{c}\text { Infill } \mathbf{E}_{\text {density }} \\
\left(\mathbf{J} \cdot \mathbf{m m}^{-3}\right)\end{array}$ & UTS (MPa) & STD & YS (MPa) & STD & EL (\%) & STD & YM (GPa) & STD \\
\hline 160 & 38.1 & 603.9 & 9.0 & 493.8 & 10.5 & 17.3 & 1.9 & 175.1 \\
240 & 57.1 & 715.2 & 3.1 & 551.3 & 5.6 & 56.9 & 0.5 & 222.9 & 8.8 \\
320 & 76.2 & 714.0 & 2.0 & 554.9 & 2.4 & 53.4 & 1.0 & 223.8 & 10.4 \\
380 & 90.5 & 714.8 & 2.5 & 559.1 & 2.8 & 52.5 & 1.8 & 224.4 & 41.4 \\
\hline
\end{tabular}

By contrast, the as-built 316LSS produced at the other three laser powers exhibited more ductile stress-strain behaviors with relatively higher values for the YS (551.3-559.1 MPa), UTS (714.0-715.2), EL (52.5\%-56.9\%), and YM (222.9-224.4 GPa). Considering the measured standard deviations in Table 6, the average values of these tensile properties were statistically comparable (from a t-test with an alpha level of 0.05) for the 316LSS produced at $240 \mathrm{~W}, 320 \mathrm{~W}$, and $380 \mathrm{~W}$ (lowest $p$-value of 0.4629 ). This finding agrees with their comparable densities (Table 2), as well as their similar porosity characteristics of small, spherical, and isolated pores within the as-built 316LSS microstructure (Figure 6b-d). How- 
ever, it is worth mentioning that the relative density (or porosity percentage) differences between all four laser power conditions were quite small (at $\leq 2 \%$ ), which alludes to the more significant role of the porosity features on defining the mechanical behavior and properties of as-built 316LSS. In regards to this, it is interesting to note the slightly better UTS and EL properties of the as-built 316LSS produced at $240 \mathrm{~W}$, which had the finest pores (Figure 6b), relative to the $320 \mathrm{~W}$ and $380 \mathrm{~W}$ conditions. The coarsening of the isolated pores in the 316LSS microstructure was observed to have the greatest and most significant impact on the ductility with reductions of $6 \%$ and $8 \%$, respectively, in the EL for the $320 \mathrm{~W}$ and $380 \mathrm{~W}$ laser powers relative to the $240 \mathrm{~W}$ condition.

The tensile properties of the near-full-density samples produced in the present study at laser powers of $240 \mathrm{~W}, 320 \mathrm{~W}$, and $380 \mathrm{~W}$ more than adequately met the minimum specifications stipulated in ASTM F3184-16 [76] for LPB-processed 316LSS, as given in Table 4. Moreover, the mechanical properties measured in this current work for the near-full-density samples showed good agreement with the vast tensile property data in the open literature, as tabulated in Table 5 from the results of previous research studies on the LPB AM of 316LSS using different stand-alone 3D printers. In this comparison, it is noteworthy that the overall tensile properties measured for the near-full-density 316LSS manufactured using the Matsuura Lumex Avance-25 hybrid LPB process were on the high side of the reported ranges of properties from conventional stand-alone LPB technologies. The observed differences can be attributed to the additive system, LPB process parameters $\left(h_{L}, h_{S}\right.$, $v, d, P$, etc.), scan strategy, orientation, powder composition, etc. Finally, in comparing the tensile properties of 316LSS produced using hybrid (LPB) manufacturing or stand-alone LPB technologies to the equivalent wrought or cast alloys, the main issue appeared to be the ductility. As supported by the EL values in Table 5, the ductility of as-built 316LSS can fall substantially below the minimum value of $40 \%$ for the wrought equivalent alloy [71,72] and even the minimum of $30 \%$ stipulated for cast $[74,75]$ and LPB [76] products. This is because the ductility of LPB-processed 316LSS was found to be highly sensitive to remnant porosity $[99,100]$, which is unlike the high-strength (YS and UTS) properties that have been previously ascribed to a Hall-Petch (grain-boundary) strengthening effect of the fine cellular structure $[62,95]$. This corroborates the EL findings in the present study that showed a strong dependence of the ductility on the pore volume, morphology, and distribution; this points to the importance of process optimization and developing an understanding of the MPSP linkages for advancing the A/SM of 316LSS.

\subsection{Fractography}

The fractured surfaces of select tensile samples were observed by SEM to distinguish the microscopic features and mode of failure, as shown in Figure 13 for each laser power condition. The fractography of the $160 \mathrm{~W}$ sample surfaces revealed, at low magnification, layered lack of fusion defects consisting of unmelted powder particles, as well as large irregularly sized pores that were often interconnected (Figure 13a); these observations corroborate well with the macrostructural findings illustrated in Figure 6a and Figurea. By contrast, the bonded regions between these lack of fusion layers revealed, at higher magnification, a dimpled texture consisting of micro-voids (Figure 13b), which is indicative of ductile failure occurring in local regions where the fracture progressed through the cellular/grain boundary structure in the as-built 316LSS. These features (dimples and defects) on the fracture surface point to the potential of the as-built 316LSS for higher strength and ductility, which were limited in the $160 \mathrm{~W}$ tensile samples by the overriding influence of the layered defects that caused premature failure (through the layers with interconnected pores and unmelted powder) and the accompanying low mechanical performance. 

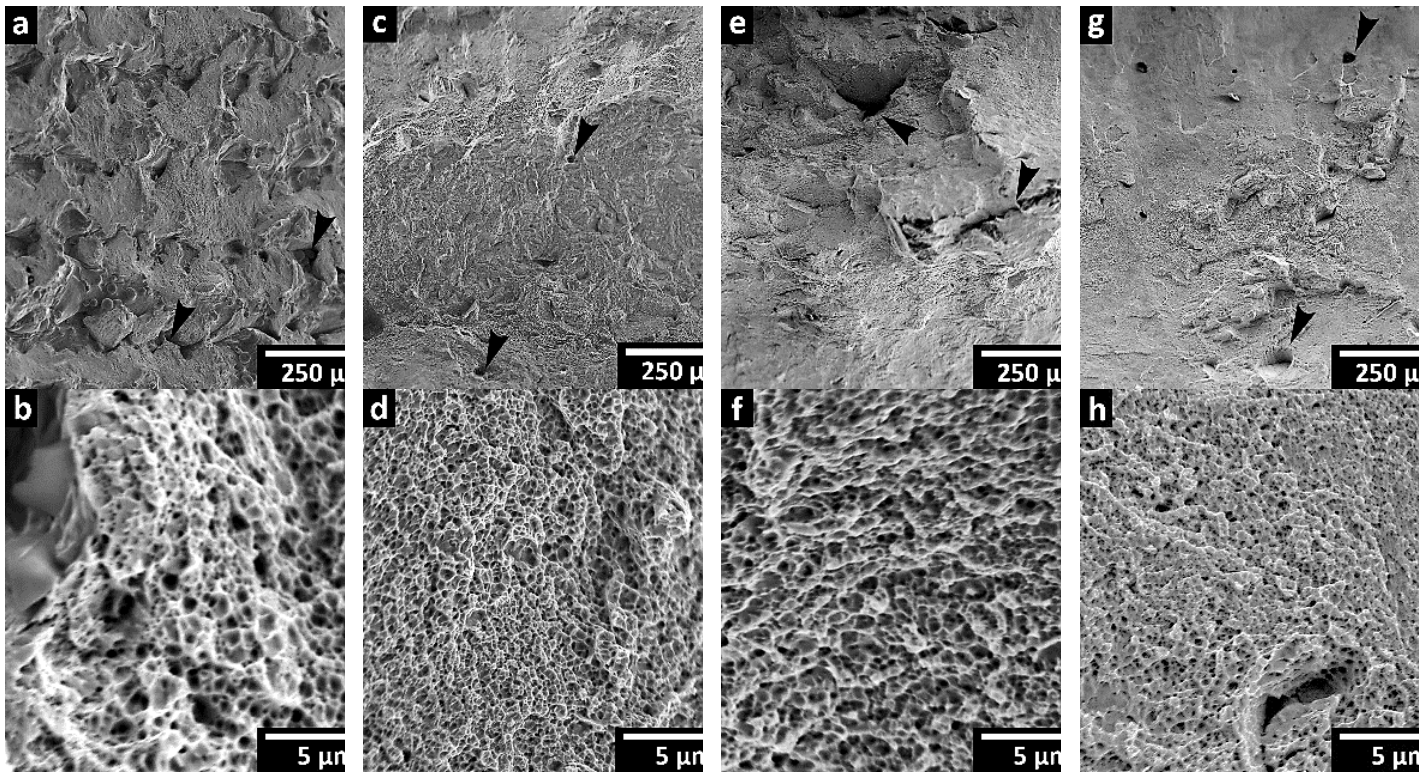

Figure 13. SEM fractographs showing the tensile fracture surfaces of as-built 316LSS produced at: (a,b) $160 \mathrm{~W},(\mathbf{c}, \mathbf{d}) 240 \mathrm{~W},(\mathbf{e}, \mathbf{f}) 320 \mathrm{~W}$, and (g,h) $380 \mathrm{~W}$.

Unlike the as-built 316LSS produced at $160 \mathrm{~W}$, the lack of fusion defects were absent from the tensile fracture surfaces of the $240 \mathrm{~W}$ (Figure 13c-d), $320 \mathrm{~W}$ (Figure 13e-f), and $380 \mathrm{~W}$ (Figure 13g-h) sample conditions (due to the adequate $\mathrm{E}_{\text {density }}$ ). At low magnification, the fracture surfaces of the near-full-density tensile samples produced at $240 \mathrm{~W}$, $320 \mathrm{~W}$, and $380 \mathrm{~W}$ showed ductile tear ridges with small rounded pores (Figure 13c,e,g) and, at high magnification, there was the predominant presence of small equiaxed dimples (Figure 13d,f,h), indicating that the main fracture mode was through nucleation, growth, and the coalescence of micro-voids. Though the overall features observed on the tensile fracture surfaces of the near-full-density samples were comparable, the $240 \mathrm{~W}$ sample exhibited the finest spherical pores relative to the $320 \mathrm{~W}$ and $380 \mathrm{~W}$ conditions, which agrees reasonably with the $\mu \mathrm{CT}$ (Figure 6) findings, macrostructural observations (Figure 8b-d), and the highest EL values. These fractographic observations in the present study for the as-built 316LSS produced using hybrid (LPB) processing corroborate well with previously reported findings for near-full-density samples built with stand-alone LPB AM [100]; specifically, low levels of remnant spherical porosity $(\leq 1 \%)$ bring about a ductile failure mode with EL values comparable to the wrought equivalent alloy, while remnant layered porosity (interconnected irregular pores with unmelted powder) at high levels $(\geq 2 \%)$ leads to premature failure with significantly lower EL. Moreover, from a microscale perspective, though it is difficult to directly relate the dimple size with ductility, the predominant presence of a healthy population of fine, uniformly distributed dimples on the tensile fracture surfaces of the near-full density 316LSS samples is typically indicative of high microstructural integrity and high plasticity [101].

\section{Discussion}

Due to the newness of A/SM, the research so far has been considerably limited on in-envelope LPB processing with the integrated micro-machining of 316LSS, relative to the large volume of studies and data on stand-alone LPB technologies, as highlighted by the tabulated property data in Table 5 . Thus, the present study strived to advance the body of knowledge on the A/SM of 316LSS by investigating the influence of inenvelope processing (LPB processing and dry micro-machining) on the geometry, surface texture/finish, density, porosity attributes, microstructure, mechanical properties, and tensile fracture/failure modes. 
For the first time, the characteristics of the manufacturer's reference 316LSS powder were evaluated and this newly generated data provides benchmarking of the feedstock material to increase build-to-build reproducibility through appropriate monitoring and quality control. Previously, a couple of studies applied the Matsuura Lumex Avance-25 A/SM system to build 316LSS samples but explored micro-machining out-of-envelope [20,21]. Through the present research, the in-envelope machining of 316LSS was investigated for the first time and the measured surface roughness ( $\mathrm{Ra}$ between $0.33 \mu \mathrm{m}$ and $0.65 \mu \mathrm{m}$ ) was equivalent to stand-alone micro-milling after LPB printing (minimized Ra between $0.55 \mu \mathrm{m}$ and $0.65 \mu \mathrm{m}$ ) [21], which is encouraging for advancing a synergistic manufacturing approach that takes advantage of the complementary elements of additive and subtractive processing.

Moreover, Mutua [23] studied the LPB processing of 316LSS with the Matsuura Lumex Avance-25 A/SM system and built samples using different conditions, namely $p=100-400 \mathrm{~W}, v=400-1000 \mathrm{~mm} \cdot \mathrm{s}^{-1}, \mathrm{~h}_{\mathrm{S}}=0.025-0.2 \mathrm{~mm}$, and $\mathrm{d}=0.05-0.3 \mathrm{~mm}$. Their design of experiments (DOE) approach identified a process map [23] with a wide optimum window for the laser power $(100 \mathrm{~W}$ to $320 \mathrm{~W})$ at fixed values for $v\left(700 \mathrm{~mm} \cdot \mathrm{s}^{-1}\right)$, $\mathrm{h}_{\mathrm{S}}(0.12 \mathrm{~mm}), \mathrm{d}(0.2 \mathrm{~mm})$, and $\mathrm{h}_{\mathrm{L}}(0.05 \mathrm{~mm})$. However, the robustness of this optimum window remained uncertain, as the basis for its validation rested on a single experimental point at $320 \mathrm{~W}$ [23]. In view of these findings, the present research study explored the robustness of the LPB process by systematically varying the laser power (from $160 \mathrm{~W}$ to $380 \mathrm{~W})$ with all the other parameters fixed $-v\left(700 \mathrm{~mm} \cdot \mathrm{s}^{-1}\right), \mathrm{h}_{\mathrm{S}}(0.12 \mathrm{~mm}), \mathrm{d}(0.2 \mathrm{~mm})$, and $h_{L}(0.05 \mathrm{~mm})$ - to match the validation point from the study by Mutua [23]. The measured roughness values ( $\mathrm{Ra}$ of $11.12 \mu \mathrm{m}-11.73 \mu \mathrm{m}$ ) in the present study for the as-built surfaces of 316LSS corroborated well with the reported Ra values of $9.95 \mu \mathrm{m}$ by Mutua [23] and $14.05 \mu \mathrm{m}$ by Avegnon et al. [20]. It is noteworthy here that the roughness after the in-envelope machining of the as-built surfaces could be reduced by more than an order of magnitude, which provides flexibility for selecting LPB parameters that are suitable/robust for maximized performance. In this regard, the evolution in the density and porosity with increasing laser power clearly indicated that the $160 \mathrm{~W}\left(\mathrm{E}_{\text {density }}=38.1 \mathrm{~J} \cdot \mathrm{mm}^{-3}\right)$ condition was insufficient for achieving near-full density in 316LSS, and (for the first time) the impact on the mechanical performance was evaluated through tensile testing and fractographic analysis. At $160 \mathrm{~W}$, the tensile properties of as-built 316LSS were compromised by the layered balling and lack of fusion defects (consisting of irregularly-shaped interconnected pores and unmelted powder) that caused premature failure. It is noteworthy here that the strength properties (YS $=493.8 \pm 10.5 \mathrm{MPa}$ and UTS $=603.9 \pm 9.0 \mathrm{MPa}$ ) met the minimum specifications for the YS (205 MPa) and UTS (515 MPa) in ASTM F3184-16 [76], but the measured EL (17.3\%) was far below the specified value of $30 \%$. Thus, the lower limit for the laser power was identified to be $240 \mathrm{~W}$ for achieving near-full density (with only small spherical pores), a ductile mechanical response, and tensile properties that met all the minimum requirements in ASTM F3184-16 [76]. The upper limit may be defined by the coarsening of the remnant spherical pores in the near-full-density microstructure of the as-built 316LSS, which was noted for the $320 \mathrm{~W}$ condition and, more so, at $380 \mathrm{~W}$, with the concomitant impact of statistically significant reductions in the EL by, respectively, $6 \%$ and $8 \%$, relative to the $240 \mathrm{~W}$ condition. However, considering the tensile property specifications in ASTM F3184-16 [76], the $240 \mathrm{~W}, 320 \mathrm{~W}$, and $380 \mathrm{~W}$ conditions more than adequately surpassed the minimum requirements for YS, UTS, and EL, though the finer pores for the $240 \mathrm{~W}$ laser power may prove to be more advantageous under cyclic loading, an important area for future research in the A/SM of 316LSS. Thus, based on the MPSP linkages explored in the present study, a more robust optimum process window could be identified for the $\mathrm{A} / \mathrm{SM}$ of 316LSS with laser powers ranging from $240 \mathrm{~W}\left(\mathrm{E}_{\text {density }}=57.1 \mathrm{~J} \cdot \mathrm{mm}^{-3}\right)$ to $380 \mathrm{~W}$ $\left(E_{\text {density }}=90.5 \mathrm{~J} \cdot \mathrm{mm}^{-3}\right)$. The in-depth analyses performed showed (for the first time) the relationship between the laser power and density/porosity evolution for the A/SM of 316LSS powder, especially with regard to the understanding of their impacts on the mechanical response, failure mode, and material allowable (property) data. 


\section{Conclusions}

The current study examined the characteristics and properties of 316LSS additively manufactured using laser powder bed (LPB) processing in-envelope with micro-machining. Based on the investigations conducted in this research, the following conclusions can be drawn:

1. The inspection of the part dimensions indicated that the overall deviations (with respect to the CAD model) were lower than $280 \mu \mathrm{m}$ and $10 \mu \mathrm{m}$ for the as-built and machined surfaces, respectively, which indicates the potential for high accuracy with in-envelope additive/subtractive processing.

2. The linear and areal surface roughness parameters on the as-built vertical side-walls had average Ra and Sa values of $11.4 \mu \mathrm{m}$ and $14.9 \mu \mathrm{m}$, respectively. After in-envelope machining, the $\mathrm{Ra}(0.33-0.65 \mu \mathrm{m})$ and $\mathrm{Sa}(0.35-0.70 \mu \mathrm{m})$ values on the machined surfaces were more than an order of magnitude lower relative to the as-built surfaces.

3. The density and porosity characteristics-examined by Archimedes, helium gas pycnometry, and X-ray $\mu \mathrm{CT}$ methods-showed the presence of a lack of fusion layers and large interconnected pores with irregular morphologies for the $160 \mathrm{~W}$ condition, which exhibited the lowest relative density of $98.0 \%$. Near-full density, with the porosity transformed to isolated spherical pores, was possible at the higher laser powers, and the measured relative densities for $240 \mathrm{~W}(99.5 \%), 320 \mathrm{~W}(99.3 \%)$, and $380 \mathrm{~W}$ $(99.0 \%)$ were statistically equivalent. LPB additive manufacturing at $240 \mathrm{~W}$ and $320 \mathrm{~W}$ showed improved densification, with the latter showing coarser pores (up to $60 \mu \mathrm{m}$ ) relative to the former. Further increases in the laser power to $380 \mathrm{~W}$ increased the volume of coarser pores (up to $100 \mu \mathrm{m}$ ), likely due to excessive energy input that promoted evaporation, the development of gas bubbles, and the eventual coalescence of many small pores into fewer larger pores. The relative densities measured for $240 \mathrm{~W}$, $320 \mathrm{~W}$, and $380 \mathrm{~W}$ were statistically equivalent and ranged from $99.0 \%$ to $99.5 \%$.

4. The as-built mechanical properties measured for the $160 \mathrm{~W}$ condition were low in hardness $\left(11.0 \pm 0.5 \mathrm{HRC}\right.$ and $\left.206.9 \pm 17.0 \mathrm{HV}_{0.5}\right)$ and, though the yield $(493.8 \mathrm{MPa})$ and ultimate tensile $(603.9 \mathrm{MPa})$ strengths met the minimum requirements of $205 \mathrm{MPa}$ and $515 \mathrm{MPa}$, respectively, in ASTM F3184-16, the measured elongation $(17.3 \%)$ was far below the specified value of $30 \%$. The higher laser powers $(240 \mathrm{~W}, 320 \mathrm{~W}$, and $380 \mathrm{~W}$ ) that led to near-full density also resulted in tensile properties that more than adequately met the requirements stipulated in ASTM F3184-16 and were comparable to 316LSS produced using stand-alone LPB processing.

5. Fractographic observations indicated a change in the fracture mode from failure through the layered lack of fusion defects and interconnected porous network (with unmelted powder particles) in the $160 \mathrm{~W}$ sample to ductile failure by micro-void formation, growth, and coalescence for the $240 \mathrm{~W}, 320 \mathrm{~W}$, and $380 \mathrm{~W}$ samples.

6. This study of the hybrid additive/subtractive manufacturing of 316LSS using a Matsuura LUMEX Avance-25 system has identified important linkages between the inenvelope processes (LPB and/or high-speed micro-machining) and the geometry, surface finish, density, porosity, microstructure, tensile properties, and fracture mode, which has led to the definition of a robust operating window for reaching high mechanical performance and near-full density, alongside typical surface finishes and tolerances of traditional subtractive manufacturing technologies.

Author Contributions: Conceptualization, S.S., J.S., M.B., P.W., J.G., R.A. and P.P.; methodology, J.S., S.S., P.W., F.B., R.A., J.G. and P.P.; software, S.S., F.B., and J.S.; validation, P.W., R.A. and M.B.; formal analysis, S.S., F.S., M.O., F.B. and P.W.; investigation, S.S., F.B., F.S. and M.O.; resources, J.S., M.B., R.A., P.P. and J.G.; data curation, S.S., F.B., M.O. and F.S.; writing-original draft preparation, S.S., P.W. and M.B.; writing—review and editing, J.G., R.A., P.P., F.B., S.S., P.W., M.B., F.S., M.O. and J.S.; visualization, S.S., M.B. and P.W.; supervision, M.B., P.W., F.B. and J.G.; project administration, M.B., P.W., J.S., R.A., P.P. and J.G.; funding acquisition, P.P., R.A., P.W., J.G. and J.S. All authors have read and agreed to the published version of the manuscript. 
Funding: This research received financial support from the Defence Technology Sustainment Program of the National Research Council Canada and the Department of National Defence (DND) under project A1-018703.

Institutional Review Board Statement: Not applicable.

Informed Consent Statement: Not applicable.

Data Availability Statement: The authors confirm that the data supporting the findings of this study are available within the article.

Acknowledgments: The authors wish to thank X. Pelletier, M. Guerin, and S. Squire of the National Research Council Canada for their technical assistance related to inspection, metallographic preparation, and mechanical testing and X. Wang from McGill University for the KGT calculation.

Conflicts of Interest: The authors declare no conflict of interest.

\section{Abbreviations}

2D Two-dimensional

3D Three-dimensional

316LSS 316 L stainless steel

AM Additive manufacturing

A/SM Additive/subtractive manufacturing

BD Build direction

CAD Computer-aided design

CRM Critical raw material

CT Computed tomography

d Spot diameter

DOE Design of experiments

EDM Electro-discharge machining

EL Elongation

$E_{\text {density }}$ Energy density

GD\&T Geometric dimensioning \& tolerancing

$\mathrm{h}_{\mathrm{L}} \quad$ Layer height

$\mathrm{h}_{\mathrm{S}} \quad$ Hatch spacing

HRC Hardness Rockwell C-scale

$\mathrm{HV}_{0.5} \quad$ Vickers hardness at $500 \mathrm{~g}$ load

KGT Kurz-Giovanola-Trivedi (KGT)

LPB Laser powder bed

$\mu \quad$ Micro

MPSP Material-process-structure-property

P Power

$\mathrm{Ra} \quad$ Arithmetic average height (line)

RPM Revolutions per minute

$\mathrm{Rq} \quad$ Root mean square height (line)

$\mathrm{Rz} \quad$ Maximum height (line)

Sa Arithmetic average height (surface)

SEM Scanning electron microscope

SLM Selective laser melting

$\mathrm{Sq} \quad$ Root mean square height (surface)

STD Standard deviation

$\mathrm{Sz} \quad$ Maximum height (surface)

TD Transverse direction

UTS Ultimate tensile strength

$v \quad$ Scanning speed

$\lambda_{c} \quad$ cut-off (wavelength)

XRD X-ray diffraction

YS Yield strength

YM Young's modulus 


\section{References}

1. Novák, P.; Bellezze, T.; Cabibbo, M.; Gamsjäger, E.; Wiessner, M.; Rajnovic, D.; Jaworska, L.; Hanus, P.; Shishkin, A.; Goel, G.; et al. Solutions of Critical Raw Materials Issues Regarding Iron-Based Alloys. Materials 2021, 14, 899. [CrossRef] [PubMed]

2. Yang, N.; Yee, J.; Zheng, B.; Gaiser, K.; Reynolds, T.; Clemon, L.; Lu, W.Y.; Schoenung, J.M.; Lavernia, E.J. Process-StructureProperty Relationships for 316L Stainless Steel Fabricated by Additive Manufacturing and Its Implication for Component Engineering. J. Therm. Spray Technol. 2016, 26, 610-626. [CrossRef]

3. Rännar, L.-E.; Koptyug, A.; Olsén, J.; Saeidi, K.; Shen, Z. Hierarchical structures of stainless steel 316L manufactured by Electron Beam Melting. Addit. Manuf. 2017, 17, 106-112. [CrossRef]

4. Mirzababaei, S.; Pasebani, S. A Review on Binder Jet Additive Manufacturing of 316L Stainless Steel. J. Manuf. Mater. Process. 2019, 3, 82. [CrossRef]

5. Krakhmalev, P.; Fredriksson, G.; Svensson, K.; Yadroitsev, I.; Yadroitsava, I.; Thuvander, M.; Peng, R. Microstructure, Solidification Texture, and Thermal Stability of 316 L Stainless Steel Manufactured by Laser Powder Bed Fusion. Metals 2018, 8, 643. [CrossRef]

6. Jiang, D.; Ning, F. Additive Manufacturing of 316L Stainless Steel by a Printing-Debinding-Sintering Method: Effects of Microstructure on Fatigue Property. J. Manuf. Sci. Eng. 2021, 143, 1-30. [CrossRef]

7. Choi, J.-P.; Shin, G.-H.; Brochu, M.; Kim, Y.-J.; Yang, S.-S.; Kim, K.-T.; Yang, D.-Y.; Lee, C.-W.; Yu, J.-H. Densification Behavior of 316L Stainless Steel Parts Fabricated by Selective Laser Melting by Variation in Laser Energy Density. Mater. Trans. 2016, 57, 1952-1959. [CrossRef]

8. Cherry, J.A.; Davies, H.M.; Mehmood, S.; Lavery, N.P.; Brown, S.G.R.; Sienz, J. Investigation into the effect of process parameters on microstructural and physical properties of 316L stainless steel parts by selective laser melting. Int. J. Adv. Manuf. Technol. 2015, 76, 869-879. [CrossRef]

9. Gray, G., III; Livescu, V.; Rigg, P.; Trujillo, C.; Cady, C.; Chen, S.; Carpenter, J.; Lienert, T.; Fensin, S. Structure/property (constitutive and spallation response) of additively manufactured 316L stainless steel. Acta Mater. 2017, 138, 140-149. [CrossRef]

10. Fayazfar, H.; Salarian, M.; Rogalsky, A.; Sarker, D.; Russo, P.; Paserin, V.; Toyserkani, E. A critical review of powder-based additive manufacturing of ferrous alloys: Process parameters, microstructure and mechanical properties. Mater. Des. 2018, 144, 98-128. [CrossRef]

11. Bajaj, P.; Hariharan, A.; Kini, A.; Kürnsteiner, P.; Raabe, D.; Jägle, E.A. Steels in additive manufacturing: A review of their microstructure and properties. Mater. Sci. Eng. A 2020, 772, 138633. [CrossRef]

12. Chniouel, A.; Giroux, P.-F.; Lomello, F.; Aubry, P.; Vasquez, É.; Hercher, O.; Maskrot, H. Influence of substrate temperature on microstructural and mechanical properties of 316L stainless steel consolidated by laser powder bed fusion. Int. J. Adv. Manuf. Technol. 2020, 111, 3489-3503. [CrossRef]

13. Yin, H.; Song, M.; Deng, P.; Li, L.; Prorok, B.C.; Lou, X. Thermal stability and microstructural evolution of additively manufactured 316L stainless steel by laser powder bed fusion at 500-800 ${ }^{\circ} \mathrm{C}$. Addit. Manuf. 2021, 41, 101981. [CrossRef]

14. Casalino, G.; Campanelli, S.; Contuzzi, N.; Ludovico, A. Experimental investigation and statistical optimisation of the selective laser melting process of a maraging steel. Opt. Laser Technol. 2015, 65, 151-158. [CrossRef]

15. Haghdadi, N.; Laleh, M.; Moyle, M.; Primig, S. Additive manufacturing of steels: A review of achievements and challenges. $J$. Mater. Sci. 2021, 56, 64-107. [CrossRef]

16. Afkhami, S.; Dabiri, M.; Piili, H.; Björk, T. Effects of manufacturing parameters and mechanical post-processing on stainless steel 316L processed by laser powder bed fusion. Mater. Sci. Eng. A 2020, 802, 140660. [CrossRef]

17. Leppert, T. Surface layer properties of AISI 316L steel when turning under dry and with minimum quantity lubrication conditions. Proc. Inst. Mech. Eng. Part B J. Eng. Manuf. 2012, 226, 617-631. [CrossRef]

18. Honeycutt, A.; Mhatre, P.; Gibson, B.; Smith, S.; Richardson, B. Iterative hybrid manufacture of a titanium alloy component Manuf. Lett. 2021, 29, 90-93. [CrossRef]

19. Matsuura, LUMEX Hybrid Metal 3D Printer. 2017. Available online: https://www.matsuurausa.com/wp-content/uploads/ LUMEX-Avance-25_-LUMEX-Avance-60_E3.0_201908.pdf (accessed on 24 January 2022).

20. Avegnon, K.; Noll, P.; Uddin, M.; Madireddy, G.; Williams, R.; Achuthan, A.; Sealy, M. Use of energy consumption during milling to fill a measurement gap in hybrid additive manufacturing. Addit. Manuf. 2021, 46, 102167. [CrossRef]

21. Afazov, S.; Ceesay, L.; Larkin, O.; Berglind, L.; Denmark, W.; Ozturk, E. A methodology for precision manufacture of a nozzle using hybrid laser powder-bed fusion: A case study. Proc. Inst. Mech. Eng. Part B J. Eng. Manuf. 2020, 235, 751-760. [CrossRef]

22. Ahmad, N.; Enemuoh, E.U. Energy modeling and eco impact evaluation in direct metal laser sintering hybrid milling. Heliyon 2020, 6, e03168. [CrossRef] [PubMed]

23. Mutua, J.M. 3D Additive Manufacturing, Microstructure, and Mechanical Properties of High Performance Materials; Tottori University: Tottori, Japan, 2018; p. 123.

24. ASTM, B213-17 Standard Test; Methods for Flow Rate of Metal Powders Using the Hall Flowmeter Funnel. ASTM International: West Conshohocken, PA, USA, 2017.

25. ASTM, B964-16 Standard Test; Methods for Flow Rate of Metal Powders Using the Carney Funnel. ASTM International: West Conshohocken, PA, USA, 2016.

26. ASTM, B212-17 Standard Test; Method for Apparent Density of Free-Flowing Metal Powders Using the Hall Flowmeter Funnel. ASTM International: West Conshohocken, PA, USA, 2017. 
27. ASTM, B417-18 Standard Test; Method for Apparent Density of Non-Free-Flowing Metal Powders Using the Carney Funnel. ASTM International: West Conshohocken, PA, USA, 2018.

28. Carr, R.L. Evaluating flow properties of solids. Chem. Eng. 1965, 18, 163-168.

29. Lumay, G.; Boschini, F.; Traina, K.; Bontempi, S.; Remy, J.-C.; Cloots, R.; Vandewalle, N. Measuring the flowing properties of powders and grains. Powder Technol. 2012, 224, 19-27. [CrossRef]

30. Muñiz-Lerma, J.A.; Nommeots-Nomm, A.; Waters, K.E.; Brochu, M. A Comprehensive Approach to Powder Feedstock Characterization for Powder Bed Fusion Additive Manufacturing: A Case Study on AlSi7Mg. Materials 2018, 11, 2386. [CrossRef]

31. Yablokova, G.; Speirs, M.; Van Humbeeck, J.; Kruth, J.-P.; Schrooten, J.; Cloots, R.; Boschini, F.; Lumay, G.; Luyten, J. Rheological behavior of $\beta$-Ti and NiTi powders produced by atomization for SLM production of open porous orthopedic implants. Powder Technol. 2015, 283, 199-209. [CrossRef]

32. ISO. In Geometrical Product Specifications (GPS)—Surface Texture: Areal (ISO 25178); ISO: Geneva, Switzerland, 2012.

33. ASTM, E8/E8M-21 Standard Test; Methods for Tension Testing of Metallic Materials. ASTM International: West Conshohocken, PA, USA, 2021.

34. ASTM, B311-17 Standard Test; Method for Density of Powder Metallurgy (PM) Materials Containing Less Than Two Percent Porosity. ASTM International: West Conshohocken, PA, USA, 2017.

35. ASTM, B923-21 Standard Test; Method for Metal Powder Skeletal Density by Helium or Nitrogen Pycnometry. ASTM International: West Conshohocken, PA, USA, 2021.

36. ASM Handbook, Properties and Selection: Irons, Steels, and High Performance Alloys Section: Carbon and Low-Alloy Steels; ASM International: West Conshohocken, PA, USA, 1990; Volume 1.

37. Sarafan, S.; Wanjara, P.; Lévesque, J.-B.; Gholipour, J.; Champliaud, H.; Mathieu, L. Residual Stresses, Microstructure, and Mechanical Properties of EB-Welded 90-mm-Thick UNS S41500 Martensitic Stainless Steel after PWHT. Mater. Perform. Charact. 2019, 8. [CrossRef]

38. Anderson, M.; Bridier, F.; Gholipour, J.; Jahazi, M.; Wanjara, P.; Bocher, P.; Savoie, J. Mechanical and Metallurgical Evolution of Stainless Steel 321 in a Multi-step Forming Process. J. Mater. Eng. Perform. 2016, 25, 1526-1538. [CrossRef]

39. ISO, 8249:2018. Welding-Determination of Ferrite Number (FN) in Austenitic and Duplex Ferritic-Austenitic Cr-Ni Stainless Steel Weld Metals; International Institute of Welding: Berlin, Germany, 2018.

40. AWS, A4.2M:2020 Standard Test; Procedures for Calibrating Magnetic Instruments to Measure Delta Ferrite Content of Austenitic and Duplex Ferritic-Austenitic Stainless Steel Weld Metal. American Welding Society: Miami, FL, USA, 2020.

41. ASTM, E18-20 Standard Test; Methods for Rockwell Hardness of Metallic Materials. ASTM International: West Conshohocken, PA, USA, 2020

42. ASTM, E384-17 Standard Test; Method for Microindentation Hardness of Materials. ASTM international West: Conshohocken, PA, USA, 2017.

43. Sarafan, S.; Wanjara, P.; Gholipour, J.; Champliaud, H.; Mathieu, L. Mehanical Properties of Electron Beam Welded Joints in Thick Gage CA6NM Stainless Steel. J. Mater. Eng. Perform. 2017, 26, 4768-4780. [CrossRef]

44. Kozak, J.; Zakrzewski, T. Accuracy problems of additive manufacturing using SLS/SLM processes. AIP Conf. Proc. 2018, 2017, 020010. [CrossRef]

45. Harcarik, M.; Jankovych, R. Relationship between values of profile and areal surface texture parameters. MM Sci. J. 2016, 5, 1659-1662. [CrossRef]

46. He, B.; Ding, S.; Shi, Z. A comparison between profile and areal surface roughness parameters. Metrol. Meas. Syst. 2021, 28, 413-438.

47. Jiménez, A.; Bidare, P.; Hassanin, H.; Tarlochan, F.; Dimov, S.; Essa, K. Powder-based laser hybrid additive manufacturing of metals: A review. Int. J. Adv. Manuf. Technol. 2021, 114, 63-96. [CrossRef]

48. Huckstepp, A. Surface Roughness-A Guide to Metal Additive Manufacturing by Digital Alloys. 2019. Available online: https:/ / manufactur3dmag.com/surface-roughness-a-guide-to-metal-additive-manufacturing-by-digital-alloys / (accessed on 24 January 2022).

49. De Terris, T.; Andreau, O.; Peyre, P.; Adamski, F.; Koutiri, I.; Gorny, C.; Dupuy, C. Optimization and comparison of porosity rate measurement methods of Selective Laser Melted metallic parts. Addit. Manuf. 2019, 2, 802-813. [CrossRef]

50. Sarafan, S.; Wanjara, P.; Gholipour, J.; Bernier, F.; Osman, M.; Sikan, F.; Molavi-Zarandi, M.; Soost, J.; Brochu, M. Evaluation of Maraging Steel Produced Using Hybrid Additive/Subtractive Manufacturing. J. Manuf. Mater. Process. 2021, 5, 107. [CrossRef]

51. Zhang, B.; Li, Y.; Bai, Q. Defect Formation Mechanisms in Selective Laser Melting: A Review. Chin. J. Mech. Eng. 2017, 30, 515-527. [CrossRef]

52. Pekok, M.A.; Setchi, R.; Ryan, M.; Han, Q.; Gu, D. Effect of process parameters on the microstructure and mechanical properties of AA2024 fabricated using selective laser melting. Int. J. Adv. Manuf. Technol. 2020, 112, 175-192. [CrossRef]

53. Wanjara, P.; Backman, D.; Sikan, F.; Gholipour, J.; Amos, R.; Patnaik, P.; Brochu, M. Microstructure and Mechanical Properties of Ti-6Al-4V Additively Manufactured by Electron Beam Melting with 3D Part Nesting and Powder Reuse Influences. J. Manuf. Mater. Process. 2022, 6, 21. [CrossRef]

54. Zhang, M.; Sun, C.-N.; Zhang, X.; Wei, J.; Hardacre, D.; Li, H. High cycle fatigue and ratcheting interaction of laser powder bed fusion stainless steel 316L: Fracture behaviour and stress-based modelling. Int. J. Fatigue 2019, 121, 252-264. [CrossRef] 
55. Hao, L.; Dadbakhsh, S.; Seaman, O.; Felstead, M. Selective laser melting of a stainless steel and hydroxyapatite composite for load-bearing implant development. J. Mater. Process. Technol. 2009, 209, 5793-5801. [CrossRef]

56. Zhong, Y.; Liu, L.; Wikman, S.; Cui, D.; Shen, Z. Intragranular cellular segregation network structure strengthening 316L stainless steel prepared by selective laser melting. J. Nucl. Mater. 2016, 470, 170-178. [CrossRef]

57. Saeidi, K.; Gao, X.; Zhong, Y.; Shen, Z. Hardened austenite steel with columnar sub-grain structure formed by laser melting Mater. Sci. Eng. A 2015, 625, 221-229. [CrossRef]

58. DebRoy, T.; Wei, H.L.; Zuback, J.S.; Mukherjee, T.; Elmer, J.W.; Milewski, J.O.; Beese, A.M.; Wilson-Heid, A.; De, A.; Zhang, W Additive manufacturing of metallic components-process, structure and properties. Prog. Mater. Sci. 2018, 92, 112-224. [CrossRef]

59. Casati, R.; Lemke, J.; Vedani, M. Microstructure and Fracture Behavior of 316L Austenitic Stainless Steel Produced by Selective Laser Melting. J. Mater. Sci. Technol. 2016, 32, 738-744. [CrossRef]

60. Suryawanshi, J.; Prashanth, K.; Ramamurty, U. Mechanical behavior of selective laser melted 316L stainless steel. Mater. Sci. Eng. A 2017, 696, 113-121. [CrossRef]

61. Lippold, J.C. Solidification behavior and cracking susceptibility of pulsed-laser welds in austenitic stainless steels. Weld. J. 1994, 73,129 .

62. Bartolomeu, F.; Buciumeanu, M.; Pinto, E.; Alves, N.; Carvalho, O.; Silva, F.S.; Miranda, G. 316L stainless steel mechanical and tribological behavior-A comparison between selective laser melting, hot pressing and conventional casting. Addit. Manuf. 2017, 16, 81-89. [CrossRef]

63. Liverani, E.; Toschi, S.; Ceschini, L.; Fortunato, A. Effect of selective laser melting (SLM) process parameters on microstructure and mechanical properties of 316L austenitic stainless steel. J. Mater. Process. Technol. 2017, 249, 255-263. [CrossRef]

64. Saeidi, K.; Gao, X.; Lofaj, F.; Kvetková, L.; Shen, Z. Transformation of austenite to duplex austenite-ferrite assembly in annealed stainless steel 316L consolidated by laser melting. J. Alloy. Compd. 2015, 633, 463-469. [CrossRef]

65. Tucho, W.M.; Lysne, V.H.; Austbø, H.; Sjolyst-Kverneland, A.; Hansen, V. Investigation of effects of process parameters on microstructure and hardness of SLM manufactured SS316L. J. Alloy. Compd. 2018, 740, 910-925. [CrossRef]

66. Wang, D.; Song, C.; Yang, Y.; Bai, Y. Investigation of crystal growth mechanism during selective laser melting and mechanical property characterization of 316 L stainless steel parts. Mater. Des. 2016, 100, 291-299. [CrossRef]

67. Yadollahi, A.; Shamsaei, N.; Thompson, S.M.; Seely, D.W. Effects of process time interval and heat treatment on the mechanical and microstructural properties of direct laser deposited 316 L stainless steel. Mater. Sci. Eng. A 2015, 644, 171-183. [CrossRef]

68. Zuback, J.; Debroy, T. The Hardness of Additively Manufactured Alloys. Materials 2018, 11, 2070. [CrossRef] [PubMed]

69. David, S.; Vitek, J.; Reed, R.; Hebble, T. Effect of Rapid Solidification on Stainless Steel Weld Metal Microstructures and Its Implications on the Schaeffler Diagram; Oak Ridge National Lab: Oak Ridge, TN, USA, 1987. [CrossRef]

70. Qu, H.; Li, J.; Zhang, F.; Bai, J. Anisotropic cellular structure and texture microstructure of 316L stainless steel fabricated by selective laser melting via rotation scanning strategy. Mater. Des. 2022, 215, 110454. [CrossRef]

71. ASTM, A240/A240M-20a, Standard Test; Specification for Chromium and Chromium-Nickel Stainless Steel Plate, Sheet, and Strip for Pressure Vessels and for General Applica-tions. ASTM International: West Conshohocken, PA, USA, 2020.

72. ASTM, A666-15 Standard Test; Specification for Annealed or Cold-Worked Austenitic Stainless Steel Sheet, Strip, Plate, and Flat Bar. ASTM International: West Conshohocken, PA, USA, 2015.

73. Song, R.-B.; Xiang, J.-Y.; Hou, D.-P. Characteristics of Mechanical Properties and Microstructure for 316L Austenitic Stainless Steel. J. Iron Steel Res. Int. 2011, 18, 53-59. [CrossRef]

74. ASTM, A743/A743M-21 Standard Test; Specification for Castings, Iron-Chromium, Iron-Chromium-Nickel, Corrosion Resistant, for General Application materials. ASTM International: West Conshohocken, PA, USA, 2021.

75. MatWeb. Cast Stainless Steel CF3M. Available online: http://www.matweb.com/search/DataSheet.aspx?MatGUID=618119 4ebe234da69f7a3f7983bdf278\&ckck=1 (accessed on 24 January 2022).

76. ASTM, F3184-16 Standard Test; Specification for Additive Manufacturing Stainless Steel Alloy (UNS S31603) with Powder Bed Fusion. ASTM International: West Conshohocken, PA, USA, 2016.

77. MatWeb. Proto Labs 316 L Stainless Steel-DMLS. Available online: http://www.matweb.com/search/datasheet.aspx?matguid= 495f16858c19459d97538c43d93f8aa0 (accessed on 24 January 2022).

78. Protolabs. Direct Metal Laser Sintering Stainless Steel 316 L Product Specifications. 2020. Available online: https://www. protolabs.com/media/1019181/stainless-steel-3161-material-spec-data-sheet.pdf (accessed on 24 January 2022).

79. SteelExpress-Limited, Steel Hardness Conversion Table. Available online: https:/ /www.scribd (accessed on 24 January 2022).

80. Kamariah, M.S.I.N.; Harun, W.S.W.; Khalil, N.Z.; Ahmad, F.; Ismail, M.H.; Sharif, S. Effect of heat treatment on mechanical properties and microstructure of selective laser melting 316L stainless steel. IOP Conf. Series Mater. Sci. Eng. 2017, 257, 012021. [CrossRef]

81. Tolosa, I.; Garciandía, F.; Zubiri, F.; Zapirain, F.; Esnaola, A. Study of mechanical properties of AISI 316 stainless steel processed by "selective laser melting", following different manufacturing strategies. Int. J. Adv. Manuf. Technol. 2010, 51, 639-647. [CrossRef]

82. Sun, Z.; Tan, X.; Tor, S.B.; Yeong, W.Y. Selective laser melting of stainless steel 316L with low porosity and high build rates. Mater. Des. 2016, 104, 197-204. [CrossRef]

83. Eliasu, A.; Czekanski, A.; Boakye-Yiadom, S. Effect of laser powder bed fusion parameters on the microstructural evolution and hardness of 316L stainless steel. Int. J. Adv. Manuf. Technol. 2021, 113, 2651-2669. [CrossRef] 
84. Saeidi, K.; Kvetková, L.; Lofaj, F.; Shen, Z. Austenitic stainless steel strengthened by the in situ formation of oxide nanoinclusions. RSC Adv. 2015, 5, 20747-20750. [CrossRef]

85. Saeidi, K.; Akhtar, F. Microstructure-Tailored Stainless Steels with High Mechanical Performance at Elevated Temperature In Stainless Steels and Alloys; IntechOpen: London, UK, 2018. [CrossRef]

86. Renishaw. Data Sheets-Additive Manufacturing SS 316 L-0407 Powder for Additive Manufacturing. 2017. Available online: File: / / /C:/Users/Sarafans/Downloads/H-5800-3001-01-A_SS_316L-0407_material_data_sheet.pdf (accessed on 24 January 2022).

87. Brytan, Z. Comparison of Vacuum Sintered and Selective Laser Melted Steel AISI 316 L. Arch. Met. Mater. 2017, 62, 2125-2131. [CrossRef]

88. EOS. Material Data Sheet_EOS StainlessSteel 316 L 2017. Available online: https:/ / www.eos.info/03_system-related-assets / material-related-contents/metal-materials-and-examples/metal-material-datasheet/stainlesssteel/ss-3161_9011-0032_m100 _material_data_sheet_flexline_12-17_en.pdf (accessed on 24 January 2022).

89. EOS. Material Data Sheet_EOS StainlessSteel 316 L. 2014. Available online: http://www.e-manufacturing.it/downloads/EOS_ StainlessSteel_316L.pdf (accessed on 24 January 2022).

90. EOS. EOS StainlessSteel 316L_Material Data Sheet. 2020. Available online: https://www.eos.info/03_system-related-assets/ material-related-contents/metal-materials-and-examples/metal-material-datasheet/stainlesssteel/material_datasheet_eos_ stainlesssteel_3161_en_web.pdf (accessed on 24 January 2022).

91. EOS. Material Data Sheet-EOS StainlessSteel 316L 2018. Available online: https://www.3ddt.com.tr/wp-content/uploads / 20 20/02/EOS_SS_316L_9011-0032_M400-4_Material_data_sheet_06-18_en.pdf (accessed on 24 January 2022).

92. Buchanan, C.; Matilainen, V.-P.; Salminen, A.; Gardner, L. Structural performance of additive manufactured metallic material and cross-sections. J. Constr. Steel Res. 2017, 136, 35-48. [CrossRef]

93. Zhang, M.; Sun, C.-N.; Zhang, X.; Goh, P.C.; Wei, J.; Hardacre, D.; Li, H. Fatigue and fracture behaviour of laser powder bed fusion stainless steel 316L: Influence of processing parameters. Mater. Sci. Eng. A 2017, 703, 251-261. [CrossRef]

94. Solutions, SLM. 3D METALS-Non Ferrous, Tool Steel, Stainless Steel and Light Alloys. 2018. Available online: https://www. forecast3d.com/wp-content/uploads/2018/01/Metal-Powders-SLM-Solutions.pdf (accessed on 24 January 2022).

95. Mertens, A.; Reginster, S.; Contrepois, Q.; Dormal, T.; Lemaire, O.; Lecomte-Beckers, J. Microstructures and Mechanical Properties of Stainless Steel AISI 316L Processed by Selective Laser Melting. Mater. Sci. Forum 2014, 783-786, 898-903. [CrossRef]

96. Hitzler, L.; Hirsch, J.; Heine, B.; Merkel, M.; Hall, W.; Öchsner, A. On the Anisotropic Mechanical Properties of Selective Laser-Melted Stainless Steel. Materials 2017, 10, 1136. [CrossRef]

97. ConceptLaser. CL 20ES Stainless Steel. 2018. Available online: https://5.imimg.com/data5/UP/TW/LD/SELLER-44066181/gecl-20es-3161-concept-laser-additive-manufacturing-material.pdf (accessed on 24 January 2022).

98. Wang, Y.M.; Voisin, T.; McKeown, J.; Ye, J.; Calta, N.; Li, Z.; Zeng, Z.; Zhang, Y.; Chen, W.; Roehling, T.T.; et al. Additively manufactured hierarchical stainless steels with high strength and ductility. Nat. Mater. 2017, 17, 63-71. [CrossRef]

99. Herzog, D.; Seyda, V.; Wycisk, E.; Emmelmann, C. Additive manufacturing of metals. Acta Mater. 2016, 117, 371-392. [CrossRef]

100. Carlton, H.D.; Haboub, A.; Gallegos, G.F.; Parkinson, D.Y.; MacDowell, A.A. Damage evolution and failure mechanisms in additively manufactured stainless steel. Mater. Sci. Eng. A 2016, 651, 406-414. [CrossRef]

101. Wanjara, P.; Watanabe, K.; De Formanoir, C.; Yang, Q.; Bescond, C.; Godet, S.; Brochu, M.; Nezaki, K.; Gholipour, J.; Patnaik, P. Titanium Alloy Repair with Wire-Feed Electron Beam Additive Manufacturing Technology. Adv. Mater. Sci. Eng. 2019, 2019, 1-23. [CrossRef] 